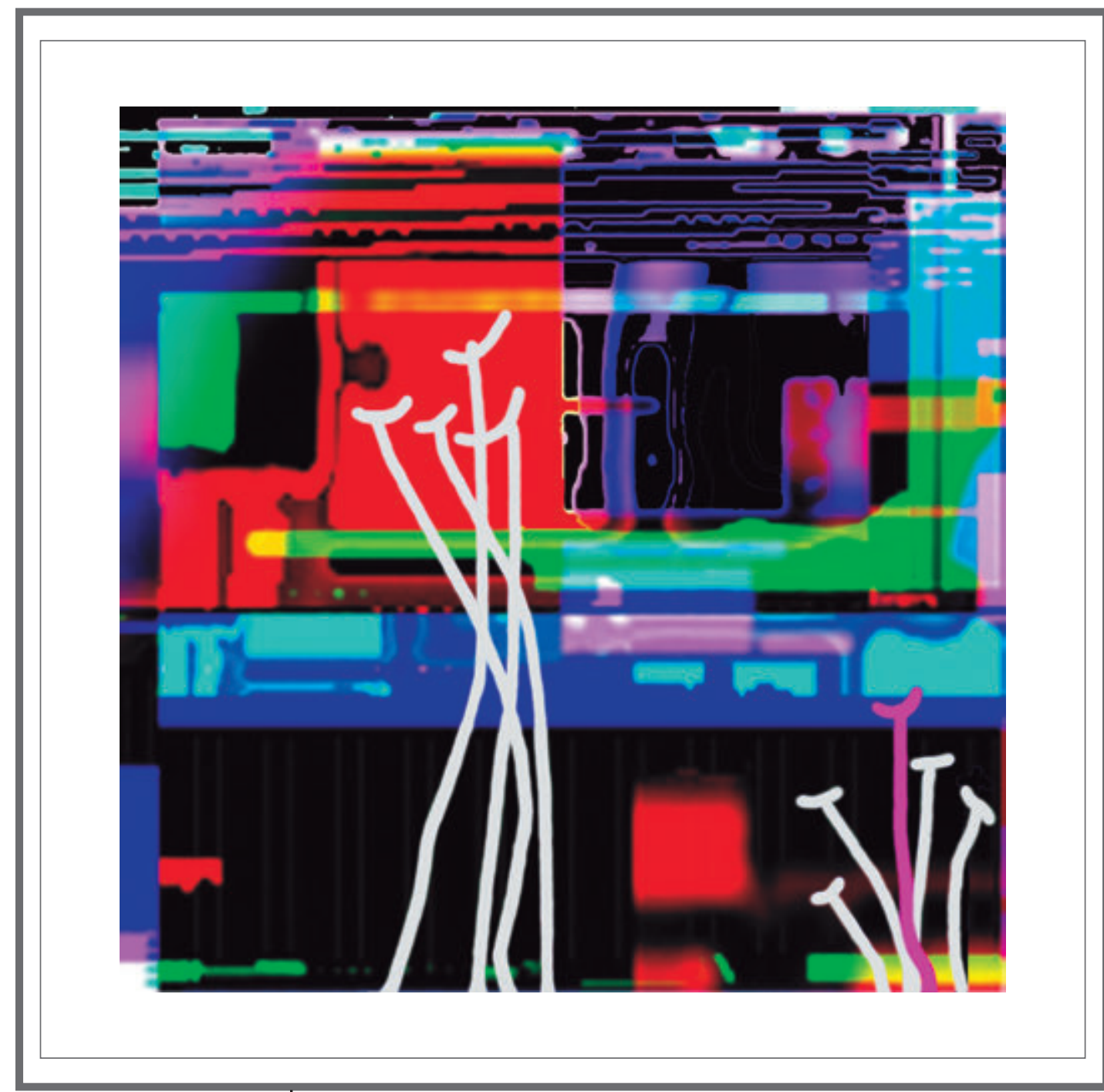

Estampa Digital

Arquitectura 10 P.M.

Título:

Jardín Digital I 


\section{Autor:}

Luis Fernando Luna

Técnica:

Impresión Digital Giclée sobre papel de Algodón 255 gr.

Medida: 40 X $40 \mathrm{~cm}$ (Estampa 30 X $30 \mathrm{~cm}$ )

Edición de 25 ejemplares

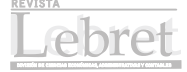




\title{
EVALUACIÓN DE LA PROYECCIÓN SOCIAL DE LA UNIVERSIDAD SANTO TOMÁS - PROGRAMA DESARROLLO COMUNITARIO*
}

ASSESMENT OF THE SOCIAL EXTENSION PROGRAM FOR
COMMUNITY DEVELOPMENT AT THE UNIVERSIDAD SANTO TOMÁS

Óscar Arcos Palma**

\begin{abstract}
Resumen
La proyección social es, junto a la investigación y la docencia, una de las funciones sustantivas de la educación superior. Desde cierto punto de vista, la proyección social expresa la forma, la magnitud y el alcance de la articulación entre el currículo y la dinámica investigativa de los programas y su manifestación en las relaciones con el entorno social, económico, político, medioambiental y cultural. El objetivo de la investigación fue evaluar la proyección social durante los últimos diez años, desde la perspectiva de uno de los programas que convoca la participación de las Facultades de la Universidad Santo Tomás en Bogotá: el Programa Desarrollo Comunitario. Sus resultados señalan la necesidad de hacer explícita la relación investigación-currículo-proyección social, superar el activismo voluntarioso de las facultades y promover una perspectiva de mayor impacto de la misma en sus relaciones con el Estado, las empresas y la comunidad.
\end{abstract}

Palabras clave: Proyección social, investigación, docencia, impacto

\begin{abstract}
The social projection, along with research and teaching, one of the substantive functions of higher education. From one point of view, the social projection expresses the shape, size and scope of the joint between the curriculum and dynamic research program and its manifestation in relations with the social, economic, political, environmental and cultural. The research objective was to evaluate the outreach over the past ten years, from the perspective of a program that organizes the participation of the Faculties of the University of St. Thomas in Bogotá: the Community Development Program. Their results indicate the need to make explicit the relationship between research, curriculum, outreach, activism willfully exceed the powers and promote a greater impact perspective of it in its relations with the state, business and community.
\end{abstract}

Keywords: Social projection, research, teaching, impact

* Investigación realizada en el año 2010, por el Centro de Investigaciones Económicas Louis Joseph Lebret,O.P., de la Facultad de Economía, bajo la dirección de Óscar Arcos Palma y la participación de los profesores Sánder Rangel, Decano Facultad de Estadística; Jorge Martínez Carvajal y Efraín Tunjo, Facultad de Economía; Jairo Barragán, Facultad de Contaduría; Hernando Díaz, Facultad de Cultura Física, Recreación y Deporte, Angélica Medina, Unidad de Proyección Social; y los estudiantes Federico Galvis, Carlos Laverde y Mauricio Poveda, de la Facultad de Economía. La investigación se aplicó a algunos programas de la USTA Bogotá.

** Economista. Candidato a PhD en Ciencias Económicas, Universidad Nacional de Colombia. Director del Centro de Investigaciones Louis Joseph Lebret O.P., Facultad de Economía, Universidad Santo Tomás Bogotá. 


\section{Introducción}

Este artículo contiene los aspectos relevantes de la evaluación de la proyección social de la Universidad Santo Tomás -USTA- Bogotá, a través del Programa Desarrollo Comunitario de la Unidad de Proyección Social. Dos razones motivaron la investigación: la primera, la necesidad de conocer cómo impactan en la comunidad las acciones de proyección social de la USTA; la segunda, responder a las recomendaciones que el Consejo Nacional de Acreditación-CNA- había formulado a la USTA en junio del 2008 en torno al tema de la proyección social, con motivo de la acreditación institucional.

En condiciones normales, una evaluación es posible si existen procesos previos de planeación y ejecución de programas, proyectos y actividades, e indicadores diseñados con antelación. En el caso del Programa Desarrollo Comunitario, no se encontraron evidencias de procesos de planificación, ni desde las facultades, ni desde la Unidad de Proyección Social. Frente a este vacío se adoptó la Metodología del Ciclo de Proyectos -MCP- (Figura 1) y la Matriz del Marco Lógico -MML(Anexo 1) con el fin de reconstruir los procesos de proyección social adelantados durante el periodo 2000-2010 en el programa, con base en el análisis de documentos disponibles y también de información primaria obtenida con aplicación de técnicas de grupos focales y entrevistas a profundidad realizadas a directivos de la Universidad, docentes, estudiantes y personas de las comunidades.

Figura 1. Metodología

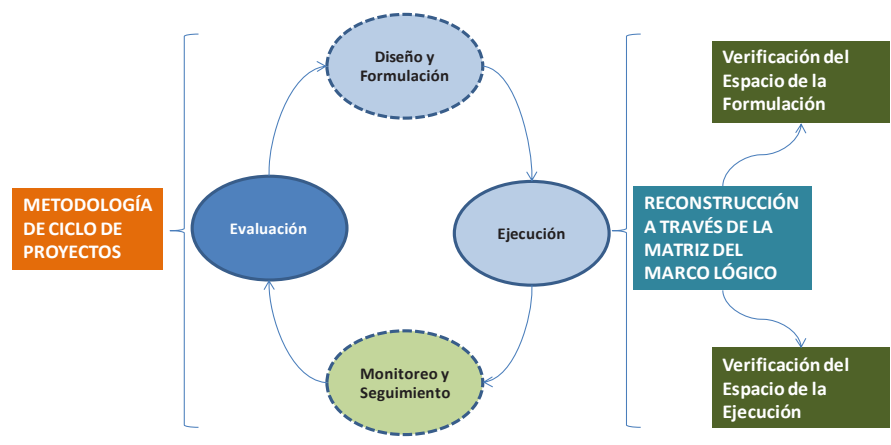

Elaboración propia 
La metodología permitió indagar acerca de los procesos de formulación de los proyectos y analizar la coherencia de los objetivos del Programa Desarrollo Comunitario y de la proyección social desde la perspectiva de las Facultades con los lineamientos del Estatuto Orgánico y del Proyecto Educativo Institucional -PEI- de la USTA. Como resultado se propuso un conjunto de indicadores para la planeación y el seguimiento de la proyección social y recomendaciones pertinentes para el fortalecimiento del Programa. La Figura 2 ilustra sobre el proceso analítico aplicado.

Figura 2. Esquema de Análisis

Itinerario analítico en los espacios de la formulación y la ejecución

(A partir de evidencias empíricas)

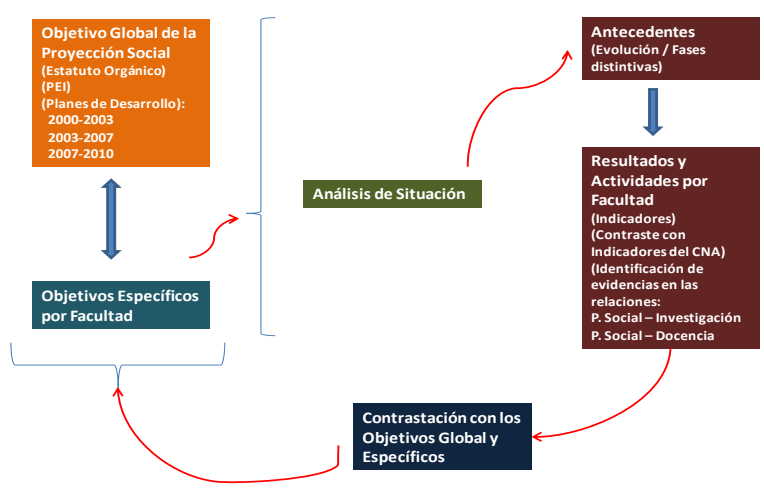

Elaboración propia

- Al aplicar la Matriz del Marco Lógico se constataron problemas de información en cantidad y calidad ${ }^{1}$ : la información es escasa, dispersa, incompleta y no respondía a patrones de organización y sistematización. La mayor parte de la información recolectada correspondía a informes incidentales de gestión.

- La inexistencia de procesos de planeación y la baja cantidad y calidad de información, dificultaron la construcción de una línea de base y también la evaluación de impacto².

1 La información disponible variaba según facultad: Economía, desde 1998; Vicerrectoría de Universidad Abierta a Distancia, desde 2002; Filosofía, Psicología y Sociología, desde el 2004; Estadística, desde 2007; Administración de Empresas, Contaduría e Ingenierías, desde 2008.

2 La planeación de la proyección social es muy reciente en algunas facultades. Contaduría Pública produjo su "Plan Estratégico de Extensión y Proyección Social” en el 2009, una vez creado el Comité de Proyección Social en esa Facultad. 
- Las Facultades y los Centros de Proyección Social, realizan un conjunto de actividades valiosas que se no se registran en ningún medio y, por lo tanto, no se hacen visibles ${ }^{3}$.

Algunos vacíos de información lograron subsanarse con las entrevistas que se realizaron a directivos, docentes y estudiantes y también con la indagación a la comunidad de las áreas de influencia de los Centros de Proyección Social, a través de la técnica de grupos focales. La información resultante permitió complementar en alguna medida las evidencias documentadas y obtener las siguientes conclusiones:

- Constatación de una diversidad de imaginarios sobre la proyección social, extensión e interacción con el medio ${ }^{4}$

- Un desencuentro relativo entre los lineamientos normativos e institucionales de la USTA y la actuación de las Facultades en proyección social

- Un activismo voluntarioso de proyección social, sin referentes precisos acerca de las problemáticas sensibles del país, desde la perspectiva de cada disciplina

- Una visión micro de la proyección social

- Ausencia de mecanismos que permitan la verificación y la evaluación permanente de las interrelaciones de la proyección social y la extensión con las funciones sustantivas de investigación y docencia.

Los hallazgos se valoran como positivos, en el sentido en que permiten a la USTA vislumbrar caminos y escenarios probables para avanzar hacia una mejor comprensión de lo que debe ser la actuación de las Facultades en proyección social y extensión y sus interrelaciones con la docencia y la investigación. También facilita a las Facultades reflexionar acerca de la naturaleza de sus relaciones con la Unidad de Proyección Social y sus programas y, de igual modo, a la Unidad le ha sido de importancia pensarse a sí misma frente a los hallazgos encontrados.

3 La experiencia de la Facultad de Economía en el Centro de Proyección Social de Cazucá, por ejemplo, tuvo alguna incidencia en los cambios del currículo. La información sobre estos efectos está en la memoria de los docentes.

4 En el documento de ASCUN, sobre indicadores de proyección social, se mencionan las diversas denominaciones que existen sobre el tema: "Proyección Social", "Extensión Universitaria", "Extensión Interactiva", "Labor de Extensión", "Relación Universidad Sociedad". La Ley 30 de Educación Superior no se compromete a llamarla de una sola manera; a ella se refiere como "Extensión o Proyección Social". La define en el Artículo 120 como "una función que comprende los programas destinados a la difusión de los conocimientos, al intercambio de experiencias, así como a las actividades de servicio tendientes a procurar bienestar general de la comunidad y la satisfacción de las necesidades de la sociedad". La USTA tiene el reto de elucidar sobre el tema y buscar los medios para que la comunidad académica se acerque a su comprensión, se apropie y actúe en ella de manera natural. 


\section{La recomendación del CNA, como referente, y los fundamentos normativos e institucionales de la Proyección Social en la USTA}

La recomendación del CNA en el tema de la proyección social, constituyó un punto de referencia para orientar el análisis. La recomendación 9, de la comunicación del CNA fechada el 24 de junio de 2008, señala:

Evaluar la perspectiva de la proyección social, que tenga en cuenta la acción combinada de los resultados de la docencia y el impacto de la investigación de los diferentes campos de conocimiento en que la universidad ofrece programas ${ }^{5,6}$.

La recomendación se sustenta en la valoració n que el CNA hizo del factor 6, pertinencia e impacto social, en particular de la característica 16, que se relaciona directamente con el objetivo de evaluación de la proyección social en el marco del Programa Desarrollo Comunitario:

La Universidad Santo Tomás de Bogotá ha definido sus politicas, estrategias y mecanismos de acción con el medio social, cultural y productivo, de suerte que pueda impactar el entorno donde se hace presente. A través de la educación a distancia la USTA hace presencia en distintas regiones del país para favorecer el acceso a la Educación Superior de estudiantes de regiones aisladas; en el caso de Bogotá, cuenta con Centros de Proyección Social en Altos de Cazucá, Monte de Galilea y el Redil. La USTA valora estas acciones como servicio a la sociedad, inspirado en el espíritu institucional y apoyado en el compromiso de estudiantes y profesores.

A juicio de los pares académicos, si bien es cierto que los proyectos asistencialistas reflejan el compromiso social de la comunidad dominicana que regenta a la Universidad, la docencia y la investigación son lo esencial de la acción universitaria y su impacto en la sociedad por la vía de los egresados, los resultados aplicables de la investigación, la divulgación científica y el compromiso social con el uso racional y ético de la tecnología, constituyen formas débilmente exploradas por la Institución como mecanismos de impacto en el entorno.

El Padre Adalmiro Arias señaló, sobre el documento citado:

"Al leer las consideraciones del CNA, uno descubre que debemos integrar conceptualmente lo que en apariencia se excluye: dos perspectivas de la proyección social: ¿Cuál es la que incumbe a la Universidad?",

5 Comunicación del CNA al Padre José Antonio Balaguera Cepeda O.P., Rector General de la Universidad Santo Tomás.

6 El Padre Adalmiro Arias O.P., analiza la recomendación 9 del CNA en el documento "Hacia la Nueva Imagen de la Proyección Social de la USTA. Documento Maestro de la Proyección Social”. Mimeo. 
en alusión al segundo párrafo de la característica 16:

“(...) si bien es cierto quelos proyectos asistencialistas reflejan el compromiso social de la comunidad dominicana que regenta a la Universidad, son la docencia y la investigación lo esencial de la acción universitaria y su impacto en la sociedad (...) los resultados aplicables de la investigación, la divulgación científica (...) constituyen formas débilmente exploradas por la Institución como mecanismos de impacto en el entorno".

Y, agregó el Padre Adalmiro:

"No es posible hacer un dualismo entre la 'Comunidad Dominicana que regenta la Universidad' y la Universidad misma como ente autónomo regulado por el CNA. Debemos integrar la rica tradición de la escuela dominicana autora fundacional de la USTA entre las fuentes del quehacer sustantivo de la USTA".

Bajo estas apreciaciones, la investigación estableció dos marcos de contraste a las afirmaciones del CNA: el primero, referido a los lineamientos normativos e institucionales de la USTA (Recuadro 1, Misión y Visión de la USTA); el segundo, a las acciones reales de proyección social que realizan las Facultades de la USTA, Bogotá, en particular a través del Programa Desarrollo Comunitario de la Unidad de Desarrollo Social.

Recuadro 1. Misión de la USTA

Misión:

Promover la formación integral de las personas, en el campo de la educación superior, mediante acciones y procesos de enseñanza-aprendizaje, investigación y proyección social, para que respondan de manera ética, creativa y crítica a las exigencias de la vida humana y estén en condiciones de aportar soluciones a la problemática y necesidades de la sociedad y del país.

[Estatuto Orgánico, marzo de 2002] 
Recuadro 2. Visión de la USTA

La visión como proyección de la Misión a mediano plazo, prospecta así la presencia y la imagen institucional de la Universidad Santo Tomás: interviene ante los organismos e instancias de decisión de alcance colectivo; se pronuncia e influye sobre los procesos que afectan la vida nacional o de las comunidades regionales, porque goza tanto de la acreditación de sus programas como de la acreditación institucional; es interlocutora de otras instituciones tanto educativas como empresariales del sector público y privado.

La comprensión humanista cristiana de la realidad colombiana y latinoamericana contemporánea, heredada de su larga tradición en el campo de la educación superior, en contexto de mundialización, inspira el quehacer de sus programas con miras a asegurar la construcción del bien común y la realización de la justicia distributiva, y así reducir la exclusión social, económica, cultural y política. Vinculada a las distintas regiones del país, a través de sus Seccionales y de sus programas de Universidad Abierta y a Distancia, es factor de desarrollo y mejoramiento de los entornos y contextos donde opera. Incorpora el uso de nuevas tecnologías educativas como herramientas para la docencia y la investigación en todos los planes de estudio, y vincula a docentes y a estudiantes en proyectos compartidos para recuperar, adaptar y generar nuevos conocimientos en orden a la solución de los nuevos problemas de la sociedad y del país.

Preparar el futuro, desde el pasado y el presente, pertenece a la razón. S.t., II-II, 47, 1).

En cuanto a los lineamientos normativos e institucionales, el Estatuto Orgánico ${ }^{7}$, señala en sus contenidos que, junto a las acciones y procesos de producción de conocimiento e investigación, la proyección social debe responder de manera ética, creativa y crítica a las exigencias de la vida humana y estar en condiciones de aportar soluciones a la problemática y necesidades de la sociedad y del país (Misión Institucional, Cap. I, Art. 7) (...) y encaminarse al mejoramiento de la vida de las personas y al desarrollo armónico de todas las dimensiones vitales y complementarias (Principios Generales, Cap. II, Art. 8).

7 http://www.usta.edu.co/documents/generales/PEI.pdf 
El Proyecto Educativo Institucional $(\mathrm{PEI})^{8}$, precisa los alcances misionales de la proyección social en estos términos:

- La "proyección social" se convierte en fin de las funciones universitarias de docencia e investigación (PEI, p. 28) (...) Si no se prioriza la pertinencia, no se pueden atender "las exigencias de la vida humana" ni esperar que la institución y las personas "estén en condiciones de aportar soluciones a la problemática y necesidades de la sociedad y del país" (PEI, p. 76).

- La gestión de la proyección social (...) vivifica y resignifica de continuo la vida académica y renueva el sentido de la investigación y de la docencia. La proyección social es, antes que oferta de servicios, esfuerzo por comprender la dinámica nacional y sus demandas, lo que exige de cada unidad académica investigar antes de planear ofertas, dentro de una clara política de servicio a todos los sectores sociales, con preferencia de los sectores más deprimidos ${ }^{9}$.

- Si bien por proyección social debe entenderse por una parte, la formación por la universidad de las nuevas generaciones, el relevo social, y, por otra, que la vida colectiva externa está presente en las distintas problemáticas, objeto de los planes de estudio, tal proyección también implica que la institución se abra a los distintos sectores sociales y les ofrezca servicios directos...

- En el capítulo de Políticas Generales para la Interacción con el Medio Externo, el PEI expresa que "Es preciso evaluar continuamente la interacción con el medio externo y discernir su incidencia en la docencia, investigación y proyección social...(p. 103) La "proyección social”, obliga a la Universidad a abrirse a todos los entornos y a aproximarse a toda exigencia de vida humana (p. 108) ${ }^{10}$.

Los lineamientos normativos e institucionales contenidos en el Estatuto Orgánico y en el PEI son claros y precisos y no se vislumbra en ellos la perspectiva asistencialista. Esta perspectiva, a la que se refiere el CNA en su informe, pudo aparecer al examinar las actividades corrientes de las Facultades a través de los programas de la Unidad de Proyección Social. Este aspecto se trata en el análisis de situación de la proyección social, desde las Facultades. 


\section{Relación entre objetivos de la Proyección Social de las Facultades y los lineamientos normativos de la USTA}

Las Facultades citan en sus documentos los lineamientos normativos establecidos por la USTA en materia de proyección social - extensión. Expresan, en términos generales, los problemas y las necesidades del país (v. gr., Derecho, presencia en el sistema de justicia Nacional y local; Ingeniería Mecánica, relación con el sector productivo Nacional ${ }^{11}$; Ingeniería Ambiental, desarrollo ambiental; Economía, articulación micro-meso-macro...). No obstante, en dicha documentación no se encontró evidencias de que las Facultades hayan definido sus propios objetivos de proyección social - de acuerdo a la naturaleza de la disciplina-, no al menos en el ámbito del Programa Desarrollo Comunitario ${ }^{12}$. Alguna excepción se hace frente a esta afirmación, al considerar que los Consultorios Jurídicos ${ }^{13}$, Psicológicos, Contables, de Estadística (...) llevan implícito un objetivo de ofrecer a la ciudadanía, en especial de bajos niveles de ingresos, servicios especializados.

Al no encontrar evidencias sobre objetivos propios de las Facultades con respecto a la proyección social ${ }^{14}$, se limitó el ejercicio de contraste entre objetivos de la Facultad y Objetivos de la USTA expresados en el PEI y en el Estatuto Orgánico. No obstante, en todas las Facultades existe una preocupación y un interés notable por refinar los ejercicios realizados hasta el presente -de ello dan cuenta los documentos sobre proyección social elaborados por algunas Facultades- y por avanzar en la coherencia de la proyección social en torno a la naturaleza de sus disciplinas y de su articulación con los objetivos misionales de la Universidad.

A propósito de la articulación de los objetivos de proyección social de una Facultad con el PEI y el Estatuto Orgánico de la USTA y de la percepción de asistencialismo social que el CNA se llevó en la pasada visita de acreditación, la Facultad de Comunicación Social se ha expresado al respecto en los siguientes términos:

“(...) asistencialismo es otro concepto, implica otras acciones diferentes, y eso es lo que justamente otros llaman proyección social (...) son discursos, pues se manejan de otra manera, pero a lo que la Universidad apunta y debería apuntarle es justamente la misma apuesta que tiene el pensamiento de Santo Tomás de Aquino expresado en el PEI, en el modelo pedagógico formulado (...) si nos guiamos de ahí, todo tendría una articulación importante (...).”15.

11 Universidad Santo Tomás Bogotá - Facultad de Ingeniería Mecánica (....). Proyección Social, p. 18.

12 Es probable que en otros ámbitos de la proyección-extensión, diferentes al programa analizado -Desarrollo Comunitario-, existan esas evidencias.

13 Reglado por normas nacionales de la educación superior.

14 Hay una aceptación general izada de que la mayor parte de los documentos sobre proyección social los han elaborado las Facultades con fines de acreditación. Esta situación hace ver la necesidad de una reflexión a profundidad sobre el tema, más allá de las contingencias de la acreditación.

15 Entrevista a la Decana de Comunicación Social. 15 de septiembre de 2010. 
Una de las conclusiones sobre el particular es la necesidad que tienen las Facultades de precisar, desde la naturaleza de sus disciplinas, los objetivos de proyección social y extensión, preferiblemente frente a problemas y necesidades del país, identificados y priorizados. La definición de objetivos facilita el diseño de estrategias y metas, relacionadas con la investigación y la docencia. La Figura 5 ilustra, con la flecha de líneas punteadas, la necesidad de superar el desencuentro que en algunas facultades existe entre los lineamientos normativos de la USTA y los objetivos específicos de la proyección social desde la perspectiva de sus programas.

Figura 5. Esquema de Análisis

\section{RELACIÓN ENTRE OBJETIVOS DE LA PROYECCIÓN SOCIAL DE LAS FACULTADES Y LOS LINEAMIENTOS NORMATIVOS DE LA USTA}

MARCO NORMATIVO INSTITUCIONAL DE LA USTA

Estatuto Orgánico

PEI

Planes de Desarrollo

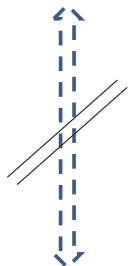

GESTIÓN DE LAS FACULTADES EN LA PROYECCIÓN SOCIAL

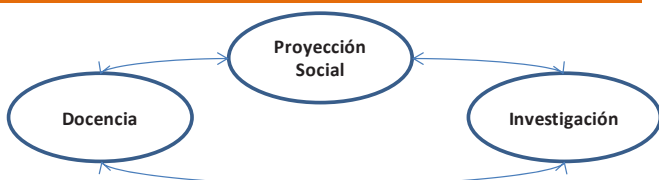

Elaboración propia

\section{Insuficientes}

Evidencias de la

Articulación entrela

gestión de las

Facultades y el Marco

Normativo

Institucional

\section{Nociones diversas de Proyección Social} la

En la página web de la USTA se define la finalidad de la proyección social como

“contribución al desarrollo Psicosocial, Económico, Ambiental y Político del país, a través de la vinculación de la academia, con sus componentes investigativo y 
docente, aplicados a los proyectos de investigación y desarrollo comunitario en beneficio de la población, que a su vez enriquecen el currículo"16.

La Universidad piensa la Proyección Social como

"función sustantiva, que hace visible a la Universidad mediante la articulación de la investigación y la docencia socialmente pertinentes; propicia el desarrollo de las capacidades intelectuales de los estudiantes, a través de estrategias curriculares y dinámicas investigativas orientadas por los docentes, las cuales permiten liderar, en conjunto, procesos sociales"17.

\section{El PEI indica que}

"La proyección social es, antes que oferta de servicios, esfuerzo por comprender la dinámica nacional y sus demandas, lo que exige de cada unidad académica investigar antes de planear ofertas, dentro de una clara política de servicio a todos los sectores sociales, con preferencia de los sectores más deprimidos".

La discusión sobre proyección social, es relativamente reciente en el país: entre los años 2006 y 2007, la Asociación Colombiana de Universidades -ASCUN- y la Red Nacional de Extensión Universitaria, realizaron una serie de talleres con representantes de cerca de 50 Instituciones de Educación Superior -IES- de todo el país, a fin de:

"proponerle al país una conceptualización de esta función (lo suficientemente abierta que incluya las particularidades y concepciones que las instituciones vienen trabajando) y unos indicadores que permitan su evaluación y divulgación".

La investigación de ASCUN, comienza por plantear que esta función de las IES colombianas es "una función sustantiva a la que se le conoce con diversos nombres: Proyección Social, Extensión Universitaria e Interacción con el Medio, entre otros". A pesar de lo anterior, ésta misma investigación concluye que al menos existe un consenso, según el cual esta es definitivamente una función sustantiva que "tiene que ver con la interacción de la institución con el entorno y su misión de contribuir al progreso de la sociedad". Según ASCUN, es común que esta función sea concebida como efecto de la articulación de la docencia y la investigación, aunque en ocasiones se gestiona como un proceso, pero adicionalmente se encuentra en no pocas ocasiones como aquella función que es la que le da la identidad a la institución de educación superior, que resulta ser el centro de su enfoque misional.

En la USTA existe una diversidad de nociones acerca de la proyección social. Algunas Facultades transitan por un proceso de reflexión acerca de la definición de

16 www.usta.edu.co

17 www.usta.edu.co 
proyección social. De las entrevistas a directivos y estudiantes y del análisis de los documentos disponibles se observa:

\section{Directivos}

- “(...) cuando hablamos de proyección social, se cruzan muchos temas (...) hay un impacto en el medio (...) tiene tres pilares: la comunidad, el estudiante y los docentes (...) en muchos casos sólo hay comunicación entre docentes y estudiantes, no entra a participar la comunidad (...)"18.

- “....) la proyección social hay que redefinirla en la Universidad. Inicialmente se tomó como algo asistencial, una concepción bastante errada (...) la proyección social la entendemos en 3 campos diferentes: (...) el egresado, con la calidad de la formación profesional, es la carta de presentación de la Universidad ante la sociedad; (...) la parte académica (...) desde la investigación; (...) participación en pasantías (...) que un profesional salga muy bien preparado para que le responda a la sociedad y que le responda de la mejor manera, esa sería la mejor proyección"19.

- "La proyección social es la misma guía de la Universidad, por cuanto la Universidad es la conciencia crítica de una sociedad, es la razón de ser de la Universidad. La USTA está iluminada por el humanismo tomista, el concepto de persona en todos los aspectos. No se entiende, en la Santo Tomás, un trabajo únicamente científico de investigación si no tiene lo uno de lo otro, porque es una mutua alimentación. La Universidad proyecta lo que produce y la sociedad proyecta hacia la Universidad lo que ha recibido, en un continuo, una retroalimentación mutua de las 2 entidades, la Universidad y la sociedad"20.

- “(...) entendemos la proyección social como la posibilidad que se tiene de irradiar en comunidades vulnerables, en egresados y fundamentalmente en sectores poblacionales que tienen afinidad con el pensamiento o la vida académica de una facultad(...)".

- "La Proyección Social la consideramos como una de las funciones sustantivas de la triada docencia-investigación-proyección social (...) como política está asociada a la investigación, para nosotros es importante que la proyección social sea un resultado de las investigaciones que se realicen en la facultad, que tenga transferencia de tecnología por decirlo de alguna forma..."21.

18 Decana Comunicación Social. Entrevista 20 de octubre.

19 Decano Facultad de Ingeniería Electrónica. Entrevista 15 de septiembre.

20 P. Vice-Rector Financiero.

21 Decano de Ingeniería Ambiental. 
- El "Objetivo es compartir con las comunidades menos favorecidas del país, los conocimientos, la voluntad y la disponibilidad de los estudiantes, docentes y directivos de Facultad de Ingeniería de Telecomunicaciones en proyectos de beneficio general, relacionados con su capacitación y experiencia disciplinar"'22.

- “...) la proyección social no es un asunto meramente accesorio o de tiempos muy puntuales o un asunto que sólo compete a los alumnos de un nivel superior (...) creemos que la proyección social debe estar articulada a la vida curricular (...)."’23

\section{Estudiantes}

- "Es el complemento de las funciones misionales de la universidad, es un elemento de consistencia entre lo planeado y lo ejecutado"24.

- "La proyección social es una de las funciones sustantivas de la universidad Santo Tomás y es el resultado de la articulación entre las dos funciones sustantivas: la docencia y la investigación, igualmente busca que los estudiantes apliquemos y desarrollemos nuestros conocimientos y capacidades intelectuales a través del trabajo con comunidades o liderando procesos sociales que contribuyan al mejoramiento de la sociedad"25.

- "Es un departamento de la Universidad que brinda herramientas a los estudiantes para el desarrollo de proyectos que estén en función exclusivamente de la comunidad"'26

- "Es la visión que se tiene para con la sociedad, es como a través de mis conocimientos puedo aportar y ayudar a la sociedad"27.

- "Son los proyectos a la comunidad que buscan relacionar la realidad construida de las organizaciones y personas"28.

\section{Documentos}

- “(...) sensibilización de los estudiantes ante la realidad que vive el país, con relación a las necesidades de las comunidades menos favorecidas y que se encuentran excluidas del desarrollo nacional y mundial"29.

Quizás las diferencias en la concepción de proyección social obedezcan en parte al perfil de cada disciplina. Habría que resaltar los aspectos comunes en

\footnotetext{
Op. Cit., p. 14-15.

Entrevista al Decano de División de Ciencias Sociales. 20 de octubre.

Estudiante de Comunicación Social.

Estudiante de Comunicación Social.

Estudiante de Ingeniería Ambiental.

Estudiante de Cultura Física, Recreación y Deporte.

Estudiante de Cultura Física, Recreación y Deporte.

9 Universidad Santo Tomás - Facultad de Ingeniería de Telecomunicaciones. Informe de Proyección para la Acreditación, 2010, p. 4.
} 
todas las Facultades: la articulación entre formación y docencia y la aplicación del conocimiento adquirido en el proceso formativo a procesos sociales.

Una de las conclusiones es la necesidad que tendría la Vicerrectoría Académica y la Unidad de Desarrollo Social de promover un proceso pedagógico ordenado (asistido) con las Facultades, para que haya una comprensión de la definición de proyección social y extensión dada por la USTA. La comunidad académica, debe tener una noción precisa sobre el tema.

\section{Proyección social desde las Facultades en el contexto del programa desarrollo comunitario}

Con la aplicación de la Matriz del Marco Lógico, se identificaron 251 proyectos (Cuadro 1)

Cuadro 1. Programa Desarrollo Comunitario, Proyectos de Proyección Social por Facultad, según tipo de proyecto $2000-2010$

\begin{tabular}{|c|c|c|c|c|c|c|c|c|c|c|}
\hline \multirow{2}{*}{$\begin{array}{c}\text { Facultad } \\
\text { yCentros dc Proyct elán } S \text { sxlal }\end{array}$} & \multicolumn{9}{|c|}{ 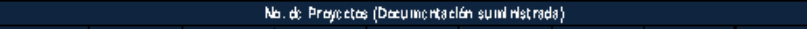 } & \multirow{2}{*}{$\begin{array}{l}\text { Pareertal } \\
\text { nertiesil }\end{array}$} \\
\hline & $\begin{array}{c}\text { Próct to } \\
\text { Prof cslonal }\end{array}$ & $\begin{array}{c}\text { Trab aja } \\
\text { Grado }\end{array}$ & $\begin{array}{c}\text { Trabajo de } \\
\text { Clasc }\end{array}$ & Investogatín & Instutuclanal & $S_{c}$, inllicras & Ganuenilo & SIn theflinlr & Tatal & \\
\hline Fecerenda & 䎑 & E. & & 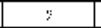 & 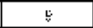 & 3 & 4 & 4 & E: & 24,3 \\
\hline Cenitlricecti(r \&) scial & & & 팔 & & & & & 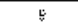 & 48 & 19,1 \\
\hline Sicciclectis & & & & 4 & & & & $x$ & $\because d$ & $9, E$ \\
\hline Certact ria Fit, lis; & & v & & 3 & $\cdot$ & & & $i$ & $\because$ & $3: 0$ \\
\hline 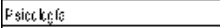 & 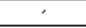 & ' & & ' & & & & $\because$ & $\because \frac{1}{4}$ & $E ; 0$ \\
\hline 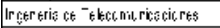 & & & & & & & & 4 & 4 & $5, \mathrm{E}$ \\
\hline 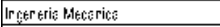 & " & & & & & & & $\frac{2}{2}$ & 24 & 5:E \\
\hline Ir & & & & & & & & $\because$ & $\because$ & 4,8 \\
\hline Ficsctifis & & & & $\because$ & & & & E & 8 & $3: 2$ \\
\hline 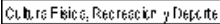 & & & & & & & & $i$ & $i$ & 2,8 \\
\hline Defectic & & & & & & & & 5 & 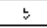 & $2: 0$ \\
\hline Fstecistica & & & & & & & & 5 & 5 & $2: 0$ \\
\hline Vilk: & & & & & & & & $\div$ & 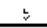 & 2,0 \\
\hline Ir çereteriq Flętreriça & . & & & & & & & $\frac{3}{2}$ & 4 & $1 ; \mathrm{E}$ \\
\hline Ir tuereriq initiertal & & & & & & & & $\because$ & $\because$ & $0: 3$ \\
\hline Aniristacile ref F nateses & & & & & & & & $\dot{\prime}$ & ' & $0: 4$ \\
\hline 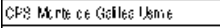 & & & & & & & & 5 & 5 & $2: 0$ \\
\hline CFE tar XXIII & & & & & & & & - & ' & $0: 4$ \\
\hline CFP Captes & & & & & & & & & l & 0,0 \\
\hline$T+1$ & $d E$ & $1 \mathrm{E}$ & 39 & 12 & 10 & 3 & 4 & 121 & 251 & $100: 0$ \\
\hline Partert alc herizantal & 18.3 & E,d & 15.5 & 4,9 & $4: 0$ & $1: 2$ & $1, \mathrm{E}$ & 43,2 & 100,0 & \\
\hline
\end{tabular}

Sus contenidos permitieron el análisis de la proyección de las Facultades en el Programa Desarrollo Comunitario. El número de documentos no refleja la dinámica de proyección social de las Facultades. Según testimonio de docentes, algunas facultades han perdido parte de sus archivos y, en otros casos, numerosas actividades realizadas no han sido sistematizadas.

Existe, en general, una relación directa entre el número de proyectos analizados y el tiempo que las Facultades llevan en actividades de proyección social en el 
Programa Desarrollo Comunitario. Economía, Comunicación Social, Sociología, Contaduría Pública y Psicología han sido las Facultades más dinámicas durante los últimos 10 años, mientras otras, como Negocios Internacionales y Estadística, apenas comienzan debido a su creación reciente. Aunque las Facultades de Filosofía y Cultura Física, Recreación y Deporte registran muy pocos documentos, han tenido una presencia muy activa en los Centros de Proyección Social. La participación de las Facultades de Ingeniería y de la VUAD en los Centros de Proyección Social, ha sido intermitente.

Del total de proyectos registrados para el análisis, 121 (48.2\%) no pudieron clasificarse en las categorías establecidas: práctica profesional, trabajos de grado, investigación, proyectos institucionales, convenios, semilleros. La mayor evidencia se registra en prácticas profesionales $(18,3 \%, 46$ proyectos) y en trabajos de clase $(15.5 \%, 39$ proyectos). Son pocos los trabajos de grado $(6.4 \%, 16$ proyectos) y de investigación $(4.8 \%, 12 \text { proyectos })^{30}$. El Cuadro 2 registra la participación de las Facultades en tres centros de proyección social.

Las cifras permiten una primera aproximación a la relación entre proyección social e investigación: es baja. Si se asocian los trabajos de grado a los de investigación, la proporción es apenas de 11.2\%. También se observó, en la documentación analizada, que el peso de las actividades (investigación, informes y otros) recae en los estudiantes, en su totalidad. Una primera conclusión al respecto, es reconocer que la relación investigación-proyección social debe comprometer a docentes y estudiantes por igual. Los docentes pueden y deben articular, desde du propia producción, la investigación con la proyección social. Las Facultades deben buscar ser consistentes con la afirmación contenida en la Visión de la USTA que señala:

“(...) y vincula a docentes y a estudiantes en proyectos compartidos para recuperar, adaptar y generar nuevos conocimientos en orden a la solución de los nuevos problemas de la sociedad y del país".

30 Algunos trabajos de investigación muestran un buen nivel de elaboración, entre ellos el de las estudiantes de filosofía MURCIA Yuryy TORRES Yury (2009). Sentido y Experiencia de la Proyección Social. Altos de Cazucá, Comuna IV. Universidad Santo Tomás, Facultad de Filosofía y Letras. Mimeo. 
Cuadro 2. Participación de las Facultades en los Centros de Proyección Social de Usme,

Cazucá, y Chapinero

\begin{tabular}{|c|c|c|c|c|c|c|}
\hline \multirow{2}{*}{\multicolumn{2}{|c|}{ Facultad de Convarieación Social }} & \multicolumn{5}{|c|}{ Alo } \\
\hline & & 2005 & 2006 & 2006 & 2009 & 2010 \\
\hline \multirow{5}{*}{ Cazucá } & No. Proyedos & 1 & & 5 & 1 & 3 \\
\hline & No. Estudiantes & 1 & & 24 & 6 & 26 \\
\hline & Pobladión & n.d. & & n.d. & n.d. & 172 \\
\hline & Teșis de Grado & 1 & & 0 & 0 & 0 \\
\hline & Investigaciones Docentes & 0 & & 0 & 0 & 0 \\
\hline \multirow{5}{*}{ Usme } & No. Proyectos & 1 & 4 & & & 2 \\
\hline & No. Estudiantes & & 6 & & & 38 \\
\hline & \begin{tabular}{|l|} 
Pobladión \\
\end{tabular} & & nd & & & n.d. \\
\hline & Tessis de Grado & & 3 & & & 2 \\
\hline & Investigaciones Docentes & & & & & \\
\hline \multirow{5}{*}{$\begin{array}{c}\text { Santo } \\
\text { Domingo }\end{array}$} & No. Proyectos & & & & 1 & \\
\hline & No. Estudiantes & & & & 25 & \\
\hline & Pobladón & & & & 15 & \\
\hline & Tesis de Grado & & & & 0 & \\
\hline & Investigaciones Docentes & & & & 0 & \\
\hline
\end{tabular}

\begin{tabular}{|c|c|c|c|c|c|}
\hline & \multirow{2}{*}{ VUNO } & \multicolumn{4}{|c|}{ Alo } \\
\hline & & 2005 & 2006 & 2007 & 2060 \\
\hline \multirow{5}{*}{ Cazucá } & No. Proyectos & 2 & 3 & & 1 \\
\hline & No. Estudiantes & 28 & 53 & & 2 \\
\hline & Población & 220 & 565 & & 10 \\
\hline & Tesis de Gado & 0 & 0 & & 0 \\
\hline & Investigaciones Docentes & 0 & 0 & & 0 \\
\hline \multirow{5}{*}{ Usme } & No. Proyectos & 1 & 1 & 1 & \\
\hline & No. Estudiantes & 28 & 28 & 29 & \\
\hline & Población & nd & nd & nd. & \\
\hline & Tesis de Grado & 3 & 3 & 2 & \\
\hline & Investigaciones Docentes & 0 & 0 & 0 & \\
\hline \multirow{5}{*}{$\begin{array}{c}\text { Santo } \\
\text { Domingo }\end{array}$} & No. Proyectos & & & & \\
\hline & No. Estudiantes & & & & \\
\hline & \begin{tabular}{|l|} 
Población \\
\end{tabular} & & & & \\
\hline & Tesis de Gado & & & & \\
\hline & Investigaciones Docentes & & & & \\
\hline
\end{tabular}

\begin{tabular}{|c|c|c|c|c|c|c|}
\hline \multirow{2}{*}{\multicolumn{2}{|c|}{ Facultad at Ecotomis }} & \multicolumn{5}{|c|}{ No } \\
\hline & & 2006 & 2007 & 2006 & 2009 & 2010 \\
\hline \multirow{5}{*}{ Cazucà } & No. Proyectos & 1 & 1 & & & \\
\hline & No. Estudiantes & nd. & 4 & & & \\
\hline & Pobladión & 6 & 150 & & & \\
\hline & Tesis de Grado & 0 & 0 & & & \\
\hline & Investigaciones Docentes & 0 & 0 & & & \\
\hline \multirow{5}{*}{ Usme } & No. Proyectos & & & 1 & 1 & 1 \\
\hline & No. Estudiantes & & & 12 & 4 & 4 \\
\hline & Pobladón & & & nd. & nd & n.d. \\
\hline & Tesis de Grado & & & 1 & 1 & 0 \\
\hline & Investigaciones Docentes & & & 0 & 0 & 1 \\
\hline \multirow{5}{*}{$\begin{array}{l}\text { Santo } \\
\text { Domingo }\end{array}$} & No. Proyectos & & 1 & & & \\
\hline & No. Estudiantes & & 4 & & & \\
\hline & Pobladón & & 5 & & & \\
\hline & Tesis de Grado & & 0 & & & \\
\hline & Investigaciones Docentes & & 0 & & & \\
\hline
\end{tabular}

\begin{tabular}{|c|c|c|c|c|c|}
\hline \multirow{2}{*}{\multicolumn{2}{|c|}{ Faculad o Derecke }} & \multicolumn{4}{|c|}{ Allo } \\
\hline & & 2005 & 2006 & 2008 & 2000 \\
\hline \multirow{5}{*}{ Cazucá } & No. Proyectos & 1 & 2 & 1 & 1 \\
\hline & No. Estudiantes & 10 & 10 & 6 & 6 \\
\hline & Población & 450 & 370 & 15 & 20 \\
\hline & Tesis de Gado & 0 & 0 & 0 & 0 \\
\hline & Investigaciones Docentes & 0 & 0 & 0 & 0 \\
\hline \multirow{5}{*}{ Usme } & No. Proyectos & & 1 & & 2 \\
\hline & No. Estudiantes & & 45 & & 6 \\
\hline & Población & & n.d. & & n.d. \\
\hline & Tesis de Grado & & 0 & & 0 \\
\hline & Investigaciones Docentes & & 0 & & 0 \\
\hline \multirow{5}{*}{$\begin{array}{l}\text { Santo } \\
\text { Domingo }\end{array}$} & No. Proyectos & & & & \\
\hline & No. Estudiantes & & & & \\
\hline & Población & & & & \\
\hline & Tesis de Grado & & & & \\
\hline & Investigaciones Docentes & & & & \\
\hline
\end{tabular}

\begin{tabular}{|c|c|c|c|c|c|c|c|c|c|}
\hline \multirow{2}{*}{\multicolumn{2}{|c|}{ Facultad de Cultura Fisica }} & \multicolumn{8}{|c|}{ Año } \\
\hline & & 2003 & 2004 & 2005 & 2006 & 2007 & 2008 & 2009 & 2010 \\
\hline \multirow{5}{*}{ Cazucá } & No. Proyectos & 1 & 1 & 2 & 3 & 2 & 1 & 1 & \\
\hline & No. Estudiantes & 1 & 1 & 4 & 2 & 3 & 2 & 1 & \\
\hline & \begin{tabular}{|l|} 
Población \\
\end{tabular} & 20 & 20 & 20 & 280 & 50 & n.d. & 30 & \\
\hline & Tesis de Grado & 0 & 0 & 0 & 0 & 0 & 0 & 0 & \\
\hline & Investigaciones Docentes & 0 & 0 & 0 & 0 & 0 & 0 & 0 & \\
\hline \multirow{5}{*}{ Usme } & No. Proyectos & & & & 2 & & & & 1 \\
\hline & No. Estudiantes & & & & 11 & & & & 1 \\
\hline & Población & & & & n.d. & & & & n.d. \\
\hline & Tesis de Grado & & & & 4 & & & & 0 \\
\hline & Investigaciones Docentes & & & & 0 & & & & 0 \\
\hline \multirow{5}{*}{$\begin{array}{l}\text { Santo } \\
\text { Domingo }\end{array}$} & No. Proyectos & & & & & 1 & 2 & & \\
\hline & No. Est udiantes & & & & & 2 & 3 & & \\
\hline & Población & & & & & 40 & 80 & & \\
\hline & Tesis de Grado & & & & & 0 & 0 & & \\
\hline & Investigaciones Docentes & & & & & 0 & 0 & & \\
\hline
\end{tabular}




\begin{tabular}{|c|c|c|c|c|c|c|}
\hline \multirow{2}{*}{\multicolumn{2}{|c|}{ Facultad de Convaleacibon Soctal }} & \multicolumn{5}{|c|}{ N/o } \\
\hline & & 2005 & 2006 & 2006 & 2009 & 2010 \\
\hline \multirow{5}{*}{ Cazucá } & No. Proyectos & 1 & & 5 & 1 & 3 \\
\hline & No. Estudiantes & 1 & & 24 & 6 & 26 \\
\hline & Pobladón & n.d. & & n.d. & n.d. & 172 \\
\hline & Tesis de Grado & 1 & & 0 & 0 & 0 \\
\hline & Investigaciones Docentes & 0 & & 0 & 0 & 0 \\
\hline \multirow{5}{*}{ Usme } & No. Proyectos & 1 & 4 & & & 2 \\
\hline & No. Estudiantes & & 6 & & & 38 \\
\hline & Pobladion & & n.d. & & & n.d. \\
\hline & Tesis de Grado & & 3 & & & 2 \\
\hline & Investigaciones Docentes & & & & & \\
\hline \multirow{5}{*}{$\begin{array}{l}\text { Santo } \\
\text { Domingo }\end{array}$} & No. Proyectos & & & & 1 & \\
\hline & No. Estudiantes & & & & 25 & \\
\hline & \begin{tabular}{|l|} 
Pobladión \\
\end{tabular} & & & & 15 & \\
\hline & Tesis de Grado & & & & 0 & \\
\hline & Investigaciones Docentes & & & & 0 & \\
\hline
\end{tabular}

\begin{tabular}{|c|c|c|c|c|c|}
\hline & \multirow{2}{*}{ VUNO } & \multicolumn{4}{|c|}{ Alo } \\
\hline & & 2005 & 2006 & 2007 & 2010 \\
\hline \multirow{5}{*}{ Cazucá } & No. Proyectos & 2 & 3 & & 1 \\
\hline & No. Estudiantes & 28 & 53 & & 2 \\
\hline & Población & 220 & 565 & & 10 \\
\hline & Tesis de Gado & 0 & 0 & & 0 \\
\hline & Investigaciones Docentes & 0 & 0 & & 0 \\
\hline \multirow{5}{*}{ Usme } & No. Proyectos & 1 & 1 & 1 & \\
\hline & No. Estudiantes & 28 & 28 & 29 & \\
\hline & \begin{tabular}{|l|l|} 
Población \\
\end{tabular} & n.d. & nd. & n.d. & \\
\hline & Tesis de Gado & 3 & 3 & 2 & \\
\hline & Investigaciones Docentes & 0 & 0 & 0 & \\
\hline \multirow{5}{*}{$\begin{array}{c}\text { Santo } \\
\text { Domingo }\end{array}$} & No. Proyectos & & & & \\
\hline & No. Estudiantes & & & & \\
\hline & Población & & & & \\
\hline & Tesis de Grado & & & & \\
\hline & Investigaciones Docentes & & & & \\
\hline
\end{tabular}

\begin{tabular}{|c|c|c|c|c|c|c|}
\hline \multirow{2}{*}{\multicolumn{2}{|c|}{ Facultad a Eeotonis }} & \multicolumn{5}{|c|}{ No } \\
\hline & & 2006 & 2007 & 2006 & 2009 & 2010 \\
\hline \multirow{5}{*}{ Cazucá } & No. Proyectos & 1 & 1 & & & \\
\hline & No. Estudiantes & n.d. & 4 & & & \\
\hline & Pobladion & 6 & 150 & & & \\
\hline & Tessis de Grado & 0 & 0 & & & \\
\hline & Investigaciones Docentes & 0 & 0 & & & \\
\hline \multirow{5}{*}{ Usme } & No. Proyectos & & & 1. & 1 & 1 \\
\hline & No. Estudiantes & & & 12 & 4 & 4 \\
\hline & \begin{tabular}{|l|} 
Pobladionn \\
\end{tabular} & & & n.d. & n.d. & n.d. \\
\hline & Tessis de Grado & & & 1 & 1 & 0 \\
\hline & Investigaciones Docentes & & & 0 & 0 & 1 \\
\hline \multirow{5}{*}{$\begin{array}{c}\text { Santo } \\
\text { Domingo }\end{array}$} & No. Proyectos & & 1 & & & \\
\hline & No. Estudiantes & & 4 & & & \\
\hline & \begin{tabular}{|l|} 
Pobladón \\
\end{tabular} & & 5 & & & \\
\hline & Tesis de Grado & & 0 & & & \\
\hline & Investigaciones Docentes & & 0 & & & \\
\hline
\end{tabular}

\begin{tabular}{|c|c|c|c|c|c|}
\hline \multirow{2}{*}{\multicolumn{2}{|c|}{ Facultad \& Derects }} & \multicolumn{4}{|c|}{ Allo } \\
\hline & & 2005 & 2000 & 2008 & 2010 \\
\hline \multirow{5}{*}{ Cazucá } & No. Proyectos & 1 & 2 & 1 & 1 \\
\hline & No. Estudiantes & 10 & 10 & 6 & 6 \\
\hline & Población & 450 & 370 & 15 & 20 \\
\hline & Tesis de Gado & 0 & 0 & 0 & 0 \\
\hline & Investigaciones Docentes & 0 & 0 & 0 & 0 \\
\hline \multirow{5}{*}{ Usme } & No. Proyectos & & 1 & & 2 \\
\hline & No. Estudiantes & & 45 & & 6 \\
\hline & Población & & nd & & n.d. \\
\hline & Tesis de Gado & & 0 & & 0 \\
\hline & Investigaciones Docentes & & 0 & & 0 \\
\hline \multirow{5}{*}{$\begin{array}{l}\text { Santo } \\
\text { Domingo }\end{array}$} & No. Proyectos & & & & \\
\hline & No. Estudiantes & & & & \\
\hline & Población & & & & \\
\hline & Tesis de Gado & & & & \\
\hline & Investigaciones Docentes & & & & \\
\hline
\end{tabular}

\begin{tabular}{|c|c|c|c|c|c|c|}
\hline \multirow{2}{*}{\multicolumn{2}{|c|}{ Facultad de Conualeación Social }} & \multicolumn{5}{|c|}{ Alo } \\
\hline & & 2005 & 2006 & 2000 & 2009 & 2010 \\
\hline \multirow{5}{*}{ Cazucá } & No. Proyectos & 1 & & 5 & 1 & 3 \\
\hline & No. Estudiantes & 1 & & 24 & 6 & 26 \\
\hline & \begin{tabular}{|l|} 
Pobladón \\
\end{tabular} & n.d. & & n.d. & n.d. & 172 \\
\hline & Tesis de Grado & 1 & & 0 & 0 & 0 \\
\hline & Investigaciones Docentes & 0 & & 0 & 0 & 0 \\
\hline \multirow{5}{*}{ Usme } & No. Proyectos & 1 & 4 & & & 2 \\
\hline & No. Estudiantes & & 6 & & & 38 \\
\hline & \begin{tabular}{|l|} 
Pobladón \\
\end{tabular} & & n.d. & & & n.d. \\
\hline & Tesis de Grado & & 3 & & & 2 \\
\hline & Investigaciones Docentes & & & & & \\
\hline \multirow{5}{*}{$\begin{array}{c}\text { Santo } \\
\text { Domingo }\end{array}$} & No. Proyectos & & & & 1 & \\
\hline & No. Estudiantes & & & & 25 & \\
\hline & \begin{tabular}{|l|} 
Pobladión \\
\end{tabular} & & & & 15 & \\
\hline & Tesis de Grado & & & & 0 & \\
\hline & Investigaciones Docentes & & & & 0 & \\
\hline
\end{tabular}

\begin{tabular}{|c|c|c|c|c|c|}
\hline & \multirow{2}{*}{ VUNO } & \multicolumn{4}{|c|}{ Alo } \\
\hline & & 2005 & 2006 & 2007 & 2010 \\
\hline \multirow{5}{*}{ Cazuca } & No. Proyectos & 2 & 3 & & 1 \\
\hline & No. Estudiantes & 28 & 53 & & 2 \\
\hline & Población & 220 & 565 & & 10 \\
\hline & Tesis de Gado & 0 & 0 & & 0 \\
\hline & Investigaciones Docentes & 0 & 0 & & 0 \\
\hline \multirow{5}{*}{ Usme } & No. Proyectos & 1 & 1 & 1 & \\
\hline & No. Estudiantes & 28 & 28 & 29 & \\
\hline & \begin{tabular}{|l|} 
Población \\
\end{tabular} & n.d. & nd. & n.d. & \\
\hline & Tesis de Grado & 3 & 3 & 2 & \\
\hline & Investigaciones Docentes & 0 & 0 & 0 & \\
\hline \multirow{5}{*}{$\begin{array}{c}\text { Santo } \\
\text { Domingo }\end{array}$} & No. Proyectos & & & & \\
\hline & No. Estudiantes & & & & \\
\hline & Población & & & & \\
\hline & Tesis de Gado & & & & \\
\hline & Investigaciones Docentes & & & & \\
\hline
\end{tabular}




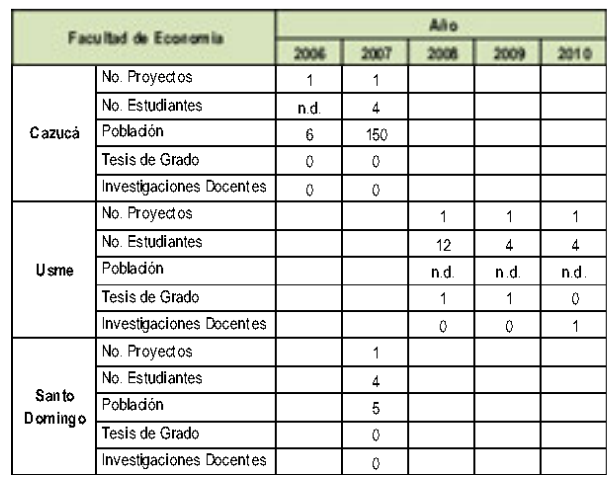

\begin{tabular}{|c|c|c|c|c|c|}
\hline \multirow{2}{*}{\multicolumn{2}{|c|}{ Faculad do Derectes }} & \multicolumn{4}{|c|}{ Alo } \\
\hline & & 2005 & 2000 & 2008 & 2006 \\
\hline \multirow{5}{*}{ Cazucá } & No. Proyectos & 1 & 2 & 1 & 1 \\
\hline & No. Estudiantes & 10 & 10 & 6 & 6 \\
\hline & \begin{tabular}{|l|} 
Población \\
\end{tabular} & 450 & 370 & 15 & 20 \\
\hline & Tesis de Grado & 0 & 0 & 0 & 0 \\
\hline & Investigaciones Docentes & 0 & 0 & 0 & 0 \\
\hline \multirow{5}{*}{ Usme } & No. Proyectos & & 1 & & 2 \\
\hline & No. Estudiantes & & 45 & & 6 \\
\hline & Población & & nd. & & n.d. \\
\hline & Tesis de Grado & & 0 & & 0 \\
\hline & Investigaciones Docentes & & 0 & & 0 \\
\hline \multirow{5}{*}{$\begin{array}{l}\text { Santo } \\
\text { Domingo }\end{array}$} & No. Proyectos & & & & \\
\hline & No. Estudiantes & & & & \\
\hline & Población & & & & \\
\hline & Tesis de Grado & & & & \\
\hline & Investigaciones Docentes & & & & \\
\hline
\end{tabular}

Fuente: Elaboración propia

La Figura 6 muestra que, mientras existe una relación implícita y explícita entre docencia e investigación, es necesario que las facultades establezcan estrategias y mecanismos que hagan explícita la relación entre proyección social e investigación y entre proyección social y docencia, verificable y medible a través de indicadores.

Figura 6. Esquema de Análisis

PROYECCIÓN SOCIAL DESDE LAS FACULTADES EN ELCONTEXTO DEL PROGRAMA DESARROLLO COMUNITARIO

\section{GESTIÓN DE LAS FACULTADES}

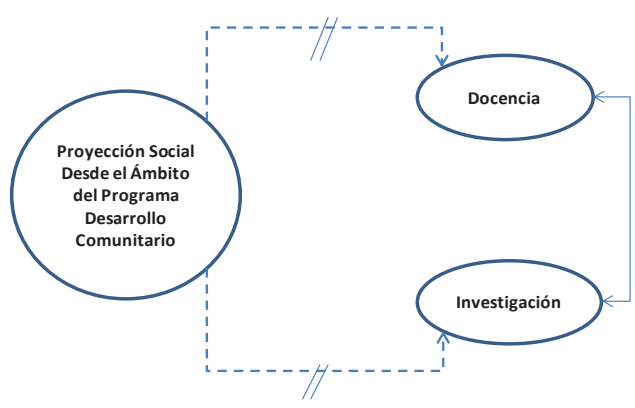

Fuente: Elaboración propia 


\subsection{Percepción de la relación entre Facultades y la Unidad de Proyección Social}

Algunas Facultades han comenzado a elucidar sobre la dimensión de la proyección social, desde su propia disciplina, otras piensan que la proyección social es de competencia de la Unidad de Proyección Social y, en esa perspectiva, conciben su rol como un apoyo a las actividades de la Unidad.

A manera de ilustración sobre el primer caso, merece una mención especial el de Ingeniería Ambiental, una Facultad relativamente nueva, que este año se propuso la iniciativa de crear un documento sobre la Proyección Social más allá de la expresión discursiva. El documento preliminar, elaborado por la docente delegada al Comité de Proyección Social en la Unidad de Proyección Social, fue sometido a discusión interna en el Comité de Investigaciones de esa Facultad. La conclusión fue que el documento no satisfacía lo que la Facultad piensa sobre la proyección social. La disyuntiva sobre la que se ha centrado la discusión en esa Facultad puede expresarse en los siguientes términos: mientras desde la perspectiva del Programa Desarrollo Comunitario se plantea el alcance de las actividades de la Facultad como "educación ambiental" dirigida a la comunidad, la Facultad piensa que la proyección social debe corresponderal perfil del ingeniero ambiental y, por tanto, las actividades de interacción con el medio deben aportar, mediante investigaciones, a los procesos de tratamiento de aguas, recuperación de suelos, tratamiento de la calidad del aire, programas de mitigación de ruidos y de contaminación visual.

La decanatura de esa Facultad ha señalado:

“(...) nos preocupa cómo nos ven, como ingeniería ambiental que va a capacitar en educación ambiental, que puede ir a sembrar unas especies, hacer una reforestación. No es el perfil del ingeniero (...). He pedido a los profesores, este semestre, que aclaremos eso ante la Unidad (...) que nuestra labor de proyección social se corresponda con el perfil del ingeniero en la Facultad (...) no podemos trabajar la parte de educación ambiental, porque no nos corresponde. El ingeniero ambiental no es un educador ambiental, debe solucionar problemas específicos ambientales que afectan los recursos naturales, generar nuevas tecnologías, promover el uso de nuevas tecnologías, el uso de energías alternativas, eso sí se corresponde con el perfil del ingeniero ambiental",

y agrega:

“Hasta dónde los docentes representantes de las facultades deben participar en las cosas propias de las facultades o en proyectos específicos que tiene la Unidad?’31.

Uno de los aspectos valiosos de la Facultad de Ingeniería Ambiental es la búsqueda de la coherencia entre investigación y proyección social. La Facultad piensa la

31 / Entrevista a la Decana de I ngeniería Ambiental, 15 de octubre de 2010. 
proyección social desde la investigación. Y, desde esa dimensión, se cuestiona su papel en los programas de la Unidad de Proyección Social. La Facultad reconoce que sus investigaciones sobre problemas concretos de comunidades distintas 32 a las comunidades de los Centros de Proyección Social de la USTA, son proyección social en el más amplio sentido del término, en concordancia con la disciplina, pero no se evidencian o visibilizan como proyección social:

“(...) eso es lo que se trata de engranar y por eso, con los profesores que coordinan esa área de proyección social y que asisten al Comité de Proyección Social, se trata de darle otro sentido a esa proyección social" ${ }^{\prime 3}$.

También la Facultad de Economía ha comenzado a pensar en transcender el tipo de actividades que ha realizado en el marco del Programa Desarrollo Comunitario. La fusión de los dos centros de investigación de la Facultad -el Centro Lebret y el Centro de Investigaciones de la Facultad, CIFE-, en uno: el Centro de Investigaciones Económicas Louis Joseph Lebret O.P., permitió a la Facultad ordenar sus líneas de investigación y sus grupos y el tema de la proyección social ha comenzado a plantearse en el marco de los proyectos de investigación. De hecho, tres proyectos de investigación presentados a la VI Convocatoria Interna este año, orientaban sus objetivos al estudio y las propuestas alternativas para superar problemas de informalidad, generación de empleo e ingresos e inclusión social al sistema de créditos, para grupos de poblaciones identificados en territorios particulares en localidades de Bogotá ${ }^{34}$.

La Facultad de Comunicación Social ha percibido en la proyección social que se realiza a través del Programa Desarrollo Comunitario, un activismo

“(...) de muchas cosas pequeñas que no están encadenadas a una estructura (...) que confunde la función universitaria y se transforma más en asistencia o asistencialismo, y es ahí donde se corre mucho riesgo"35.

Otras Facultades, como Ingeniería de Telecomunicaciones, parecen sostener el criterio de que las acciones de proyección son un apoyo a proyectos o programas de la Unidad de Proyección Social:

"Desde el punto de vista de la Unidad, las facultades son las instancias ejecutoras de los proyectos y delas actividades propias de proyección social. Cada una de

32 En la actualidad, la Facultad gestiona iniciativas relacionadas con el tratamiento del Río Tunjuelo, las curtiembres de Villa Pinzón, aguas y manejo de residuos sólidos en un municipio de Huila. También participó activamente en al elaboración del Plan de Desarrollo Ambiental de la Localidad de Chapinero en Bogotá.

33 Entrevista a la Decana de Ingeniería Ambiental, 15 de octubre de 2010.

34 Uno de esos grupos es la comunidad Afrocolombiana asentada en el centro de la ciudad con actividades económicas relacionadas con la gastronomía y la producción artesanal. Las propuestas se articulan para implementar modelos propios de desarrollo endógeno local.

35 Entrevista a la Decana de Comunicación Social. 20 de octubre de 2010. 
las Facultades deberá apoyar la labor de la Unidad acorde a la disciplina de que trate, pero articulado con el fin último que es el apoyo a las comunidades menos favorecidas ${ }^{36}(. .$.$) .$

Y añade, acerca de los Centros de Proyección Social:

“(...) es en estos sitios donde se llevan a cabo las acciones propias de las políticas de la Proyección Social de la Universidad..." ${ }^{37}$.

Un hallazgo importante: cada Facultad tiene su forma particular de realizar proyectos y procesos de proyección social, constatándose la gran diversidad del conocimiento y su quehacer como un logro y un recurso institucional. Cada Facultad desarrolla acciones que pueden catalogarse en el ámbito del Desarrollo Comunitario, con sello de investigación-proyección, pero que no se inscriben en el programa Desarrollo Comunitario que se realiza desde la Unidad de Proyección Social en sus propios Centros. Tales acciones deben visibilizarse.

\subsection{Percepción de los problemas del país que abordan las Facultades en la perspectiva de la Proyección Social}

\subsubsection{Visión General ${ }^{38}$}

La USTA busca, a partir de sus funciones sustantivas de producción de conocimiento, investigación y proyección social, y desde una perspectiva Aristotélica-Tomista, el bien común en la sociedad. Implica, en el contexto social colombiano, abordar problemáticas de pobreza, exclusión/inclusión; violencia y paz, que incluyen los temas de desplazamiento, tierras, tejido social-convivencia, tolerancia, diversidad-; infraestructura; calidad de vida; inclusión y fortalecimiento de las empresas en un contexto de competencias y mercados abiertos. Todos esos problemas de la realidad colombiana se enmarcan en la búsqueda del bien común y a ello la USTA contribuye desde sus funciones sustantivas y la interdisciplinariedad, precisan ambientes que susciten respuestas de responsabilidad social universitaria en varios frentes, entre ellos: estudiantes y docentes, a través de la formación y el perfeccionamiento profesional, con el fin de impactar directamente en la comunidad e indirectamente en la búsqueda del bien común; egresados que, con su visión humanista y su compromiso, impactan el mundo empresarial, institucional y político del país. El primer impacto de la proyección social se expresa y dimensiona en la persona.

36 Op. Cit., p. 7. El subrayado es nuestro.

37 Op. Cit., p. 7.

38 Con base en la entrevista realizada a Fr. Eduardo González O.P., Vice-Rector Académico de la USTA. 
Desde la investigación se anima al otro. Cada programa académico, desde su epistemología y a través de su propia gestión, busca la cualificación de la persona y del otro. Desde la VUAD, la visión humanista-tomista contribuye a enriquecer la realidad en 32 ciudades del país, a través de las prácticas que realizan los docentes y los trabajos de grado; los ingenieros civiles, mecánicos, ambientales, electrónicos, buscan impactar realidades desde su conocimiento; los profesionales de las distintas disciplinas académicas de la USTA, buscan impactar realidades del país al generar redes y participar en grandes temas, por ejemplo las mesas de trabajo sobre violencia y desplazamiento, en las que participa la Facultad de Derecho, la reflexión latinoamericana desde la Facultad de Filosofía, el mundo de la robótica y su rol en el mundo empresarial, desde la Facultad de Ingeniería Electrónica. La interacción con el medio permite impactar el currículo en forma dinámica, y genera áreas, criterios, contenidos, opciones de grado, diversificación académica. A ello obedece la aparición de nuevos Doctorados y Maestrías, como los creados recientemente en Derecho y Educación: son la expresión de la forma como la USTA se inserta en las realidades del país. En esas dinámicas se genera una relación virtuosa entre pregrados y posgrados que se manifiesta en la investigación.

\subsubsection{Apreciaciones acerca de problemas relevantes del País, desde las facultades, en clave de proyección social}

A través de los documentos analizados y de las entrevistas a instancias directivas de las Facultades, se obtuvo la percepción de un conocimiento general y amplio de los problemas que tiene el país y que son preocupación en cada programa académico. Una precisión de los problemas considerados relevantes para ser abordados desde cada disciplina, podría hacerse al examinar las líneas activas de investigación en cada Facultad, tarea que debería iniciarse, en la perspectiva ya abordada por las Facultades de Economía e Ingeniería Ambiental, por mencionar algunas. Al respecto, en esta última se afirma:

“(...) los problemas son muy diferentes en cada comunidad. Si estamos hablando de un municipio, debemos hacer un diagnóstico, una línea base de las condiciones del municipio y luego jerarquizar cuáles son sus prioridades. Pero, en términos generales, digamos que tenemos un problema muy serio de aguas, tratamiento de aguas residuales, el manejo de residuos. Es algo crítico en todos los municipios del país"39.

La Facultad de Comunicación Social acude a los lineamientos generales de la USTA en proyección social y del criterio de interdisciplinariedad, señala que la proyección social debe responder

39 Facultad de Ingeniería Ambiental. 
“(...) a las cuestiones macro, en el horizonte de tener un impacto real e importante para la sociedad. Es ahí donde funciona la investigación, donde cobra sentido la investigación" ${ }^{\prime 40}$.

Las apreciaciones generales acerca de los problemas relevantes del país sobre los cuales deberían tener un mayor impacto la proyección social de la USTA, se contrastaron con las opiniones -sobre el mismo tema-, de los docentes que hacen parte del Comité de Proyección Social en la Unidad de Proyección Social. La Tabla 1 muestra los resultados de la indagación a la interrogante que se formuló a los docentes en un taller realizado para el efecto el 7 de septiembre, sobre los tres problemas del país que consideraban, en su opinión, los más importantes desde la perspectiva de su Facultad. Es de resaltar en las respuesta de algunos docentes Ingeniería Ambiental, Estadística, Cultura Física, Recreación y Deporte, Filosofía (...)-, una cierta coherencia con lo expresado por sus directivos o los documentos de su Facultad y con los objetivos globales de la proyección social de la USTA.

Tabla 1. Percepción de los docentes delegados al Comité de Proyección Social Programa Desarrollo Comunitario, sobre los problemas más importantes que aborda la Facultad

\begin{tabular}{|c|c|c|c|c|c|}
\hline \multicolumn{6}{|c|}{ 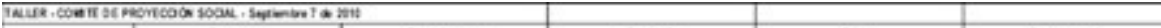 } \\
\hline \multirow[b]{2}{*}{ racutas } & motems & Camplagen & $\infty=\infty$ & Dewe & Destions \\
\hline & 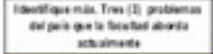 & 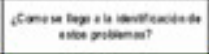 & 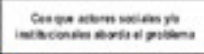 & 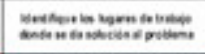 & 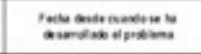 \\
\hline $\ln 0=1$ & 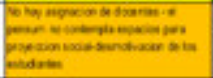 & 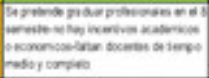 & & & \\
\hline hs Mecanica & 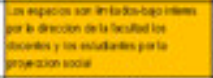 & 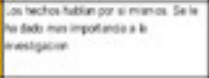 & & & \\
\hline les Anteribi & 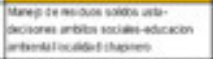 & & 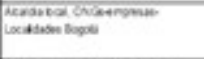 & 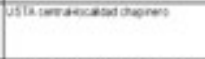 & 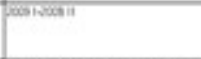 \\
\hline mo fromen & 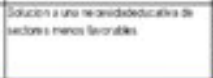 & 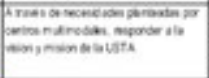 & 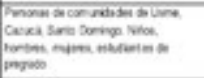 & 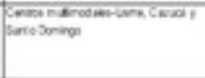 & 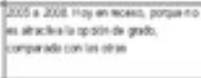 \\
\hline fowens & 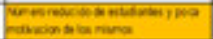 & 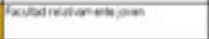 & & & \\
\hline tutabisen & 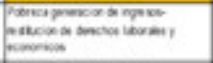 & & & & \\
\hline Conentive & 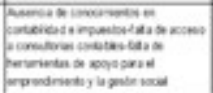 & 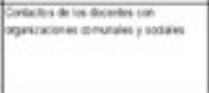 & & & \\
\hline 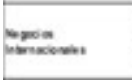 & 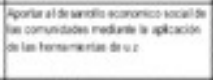 & 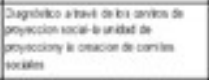 & & & \\
\hline Detentanes & 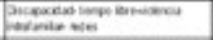 & 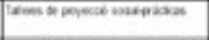 & & & \\
\hline rinewe & 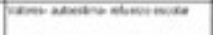 & 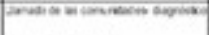 & & & \\
\hline cos reve ocener & 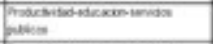 & 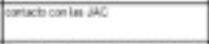 & 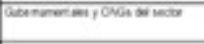 & 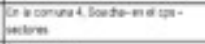 & 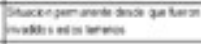 \\
\hline 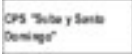 & 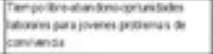 & 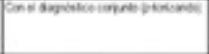 & & Dewenton & \\
\hline Cos Wear in daller & 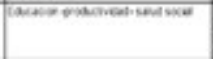 & 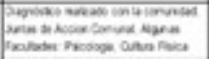 & & & \\
\hline
\end{tabular}

40 Entrevista a Decana de Comunicación Social, 15 de septiembre de 2010. 
También en las entrevistas a estudiantes, ante la pregunta. ¿A partir de su experiencia de proyección social, cuáles son en su opinión, los tres problemas más importantes a los que su facultad y su profesión deberían contribuir a solucionar? se pudo constatar dos situaciones: en una, manifestaron desconocer a cuáles problemas más importantes del país orientaba su Facultad las acciones de la proyección socialextensión, independiente de la inexistencia de un proceso de planificación en la materia; en otra, manifestaron pleno dominio acerca de los problemas sensibles que desde su disciplina se incluían en la perspectiva de la proyección social ${ }^{41}$.

Las respuestas a la pregunta: ¿Cómo llegaron a la identificación de los problemas? Según lo observado en la Tabla 1, subraya: (i) la necesidad de un ejercicio de planeación en las Facultades, para establecer concordancias entre la investigación y la proyección social; (ii) la necesidad de crear dinámicas de reflexión colectiva en las Facultades, con el fin de que estudiantes y docentes hablen un mismo lenguaje, se identifiquen con los lineamientos generales de su Facultad y de la USTA en materia de investigación-proyección social, se los apropien y contribuyan a darle el sello particular que distingue a la USTA de otros centros universitarios.

\title{
4.3 Percepción de la relación Proyección Social-Investigación, Proyección Social-Docencia
}

La relación entre Proyección Social e Investigación en la USTA se da en un contexto de diálogo permanente. La investigación en sí misma tiene un componente claro de objetivos de proyección y, de igual modo, un proceso de proyección social no se puede dar sin que exista un proceso de investigación implícito. Al respecto, la decana de comunicación afirmó:

\begin{abstract}
“(...) nuestra Facultad tiene un currículo en el que el estudiante desarrolla investigación y proyección social. Desarrolla la formación básica o la formación primordial de los medios de comunicación y desarrolla unos énfasis. En toda la trayectoria hay una línea en la formación investigativa que ésta se convierte en el núcleo problémico" ${ }^{\prime 2}$.
\end{abstract}

La Proyección Social es un vehículo de transmisión de conocimiento. Se convierte en un fin impulsado por los procesos de investigación. Justifica la importancia y seriedad de los procesos investigativos que repercutirán en un impacto positivo en las comunidades. "(...) procuramos que la proyección social no sea un asunto para concluir unas horas sino (...) proyectos que tengan que ver con la investigación"³.

Aunque en lo discursivo es clara la relación que se establece entre Enseñanza-

\footnotetext{
41 Por ejemplo, estudiantes de Ingeniería Ambiental, señalaron los problemas de saneamiento básico, educación, ordenamiento territorial y uso eficiente de recursos, como problemas prioritarios.

42 Entrevista, 15 de septiembre

43 Entrevista al Decano de División de Ciencias Sociales, 20 de octubre.
} 
Aprendizaje, Investigación y Proyección Social, la documentación revisada sobre las actividades de las Facultades en el Programa Desarrollo Comunitario no proporciona evidencias de esas relaciones. Sobre el particular se pronunció el Decano de Negocios Internacionales:

“(...) ninguna de las tres funciones esenciales son absoluta y totalmente autónomas. Uno podría adelantar actividades de investigación o de docencia o de proyección social de manera independiente, pero no necesariamente eso genera el mejor resultado. Creemos que, por lo tanto, proyección social puede y debería estar articulada no solamente con la investigación sino con el tema de docencia. Pero hay que mirar el cómo se hace, porque decirlo suena bien, pero la clave está en cómo lo evidenciamos las relaciones de esas funciones" ${ }^{\text {"4 }}$.

La Tabla 2 registra la opinión que tienen los docentes delegados al Comité de Proyección Social, acerca de las relaciones entre Proyección Social - Investigación y Proyección Social - Producción de conocimiento o Currículo. Las opiniones indican que, en términos pragmáticos, existen limitaciones para establecer con claridad el tipo de relaciones y los niveles de esas relaciones que puedan tener las tres funciones esenciales en cada Facultad. Sobre este tema se harán recomendaciones en el punto 6 de este documento.

Tabla 2. Percepción de los docentes delegados al Comité de Proyección Social- Programa Desarrollo Comunitario, sobre las relaciones de la proyección social con el currículo y con

la investigación

\begin{tabular}{|c|c|c|c|}
\hline TROATE & 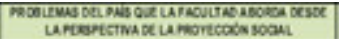 & 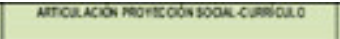 & 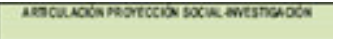 \\
\hline$\rightarrow \mathrm{CM}$ & 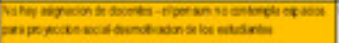 & 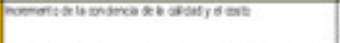 & 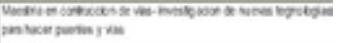 \\
\hline So the ina & 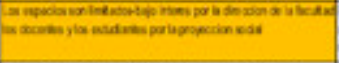 & 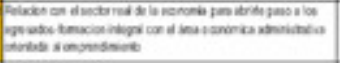 & \\
\hline to ateoest & 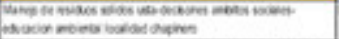 & mpasom nests & 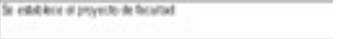 \\
\hline 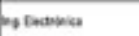 & 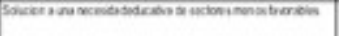 & & \\
\hline tosienes & Pobreza, emplea, ingresos & 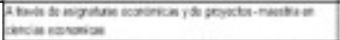 & 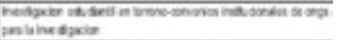 \\
\hline tondites & 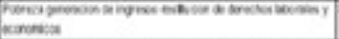 & 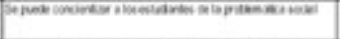 & \\
\hline Centakis & 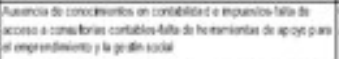 & 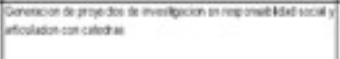 & \\
\hline 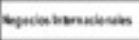 & 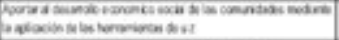 & & \\
\hline Aantaika & 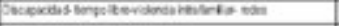 & & \\
\hline mastes & 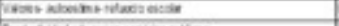 & 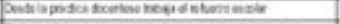 & 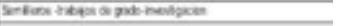 \\
\hline 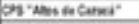 & 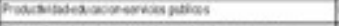 & 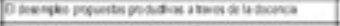 & \\
\hline 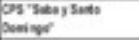 & 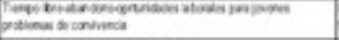 & 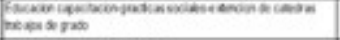 & \\
\hline OS 'Wosb de Githe' & 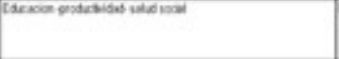 & 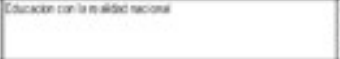 & 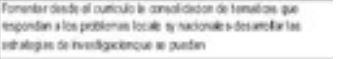 \\
\hline
\end{tabular}

44 Entrevista a Decano de Negocios Internacionales. 15 de septiembre de 2010. 


\section{El programa Desarrollo Comunitario desde el punto de vista de la comunidad}

Con la aplicación de la metodología de grupos focales, se adelantó un proceso con personas de la comunidad beneficiada de las actividades de los Centros de Proyección Social -CPS- en Usme, Soacha y Chapinero. La evaluación comprensiva se sustenta en los siguientes componentes:

\section{Componente 1}

Ejes: Educación, Salud y Servicios básicos domiciliarios

Componente 2

Ejes: Cultura y Medio Ambiente

Componente 3

Eje: Productividad

Componente 4

Eje: Relación con la Universidad

Los criterios aplicados a la evaluación comprensiva fueron:

- Evaluación de la pertinencia (congruencia de la realización misional de la Universidad Santo Tomás y el proceso de proyección social, en relación al aporte de la solución de problemáticas de la comunidad.

- Evaluación de la sostenibilidad de la intervención. En este sentido se analizó la viabilidad y sostenibilidad del proyecto con el fin de guiar y crear una línea de planeación de la proyección social, basada en una batería de indicadores.

- Población objeto: 10 a 12 usuarios por cada CPS. Comité de Proyección Social.

Los resultados del proceso se expresan en los siguientes términos: la comunidad identifica los principios asociados a la proyección social de la USTA, desde los Centros de proyección Social.

- Fortalecimiento Comunitario desde el desarrollo del conocimiento propio y afianzado con el de la academia, que sitúa al centro la persona humana.

- Reconocimiento de la importancia de la asociatividad comunitaria, la construcción del tejido social y de redes, desde una noción de bien común

- Incremento del bienestar psicosocial desde el eje de la familia nuclear y extensa

- Potenciación del emprendimiento social, como parte del logro de la justicia social y la realización de la equidad 
Las conexiones entre componentes, resultados y participaciones, permiten la integralidad del proyecto, observándose conexiones fuertes entre los componentes.

\subsection{Pertinencia}

De acuerdo a la misión institucional de la Universidad Santo Tomás, la estrategia del Programa Desarrollo Comunitario es pertinente. Debe responder a las necesidades sentidas por parte de las comunidades y el entorno: bajos niveles de cobertura de oportunidades básicas para el desarrollo humano, una baja presencia de instituciones estatales y privadas. Se reconocen aportes de la USTA en la superación de las condiciones de exclusión y vulnerabilidad de las comunidades, evidenciados en los siguientes procesos:

\begin{tabular}{|c|c|}
\hline $\begin{array}{l}\text { Necesidades y problemas de las } \\
\text { comunidades }\end{array}$ & Aporte USTA \\
\hline Bajo nivel de cobertura de servicios básicos & $\begin{array}{l}\text { Acompañamiento y organización de las } \\
\text { comunidades por la gestión de sus derechos }\end{array}$ \\
\hline $\begin{array}{l}\text { Debilitamiento de tejido social y de } \\
\text { participación en la organización de la } \\
\text { comunidad }\end{array}$ & $\begin{array}{l}\text { Fortalecimiento comunitario desde la lectura } \\
\text { y la construcción de valores y conocimiento } \\
\text { Actuación interinstitucional y en red }\end{array}$ \\
\hline $\begin{array}{l}\text { Falta de empoderamiento de los líderes en } \\
\text { las diferentes comunidades }\end{array}$ & Identificación y capacitación de líderes \\
\hline \multicolumn{2}{|l|}{ Exclusión y estigmatización social } \\
\hline $\begin{array}{l}\text { Bajo nivel de competencias y capacidades } \\
\text { académicas de educación formal }\end{array}$ & $\begin{array}{l}\text { Procesos de formación y capacitación desde } \\
\text { los ámbitos disciplinares } \\
\text { Formación en competencias tecnológicas y } \\
\text { de comunicación en lengua extranjera }\end{array}$ \\
\hline
\end{tabular}

Fuente: Elaboración propia

La pertinencia de la acción de las Facultades desde los CPS, nace en la concepción curricular para abordar de manera disciplinar los problemas de la comunidad y en que la dinámica surge y siempre se desarrolla, en el protagonismo del usuario del CPS y la relación con la USTA. Se asume que esta relación crea una base sólida y necesaria para iniciar un proceso de desarrollo humano autónomo y que, dada la poca auto-referencia reflexiva que poseían estas familias antes de la presencia de la institución, se necesitó de un agente externo en este caso las facultades por medio de las prácticas y los proyectos, entre otras modalidades de proyección social, que facilitara la generación de capacidades y competencias para el desarrollo comunitario.

El rol jugado por la Universidad Santo Tomás a través de los CPS, es fundamental para el aporte en la construcción del Estado Social de Derecho. La incidencia en 
las familias y la comunidad, es reconocida por parte de ellas mismas y le asignan un grado de identidad en el territorio a los CPS. Por supuesto, existen vacíos y sugerencias en torno a la mejora de la calidad y la infraestructura de equipamientos físicos y tecnológicos.

La estrategia de desarrollo comunitario desde las diferentes formas de intervención disciplinar, ha fortalecido los vínculos comunitarios vecinales, familiares e individuales, desde los eventos lúdicos, artísticos y de emprendimiento social con enfoque diferencial (Arroyo, Montes de Galilea). La estrategia en este sentido ha sido flexible y se ha gestionado como puente de las comunidades y la ejecución de la estrategia y no ha reemplazado la actuación del Estado y a la propia comunidad. Lo que se constituye como una fortaleza y recurso para la comunidad y se refleja en una mejor convivencia comunitaria basada en los procesos de conciliación como mecanismo de resolución de conflictos. Es de destacar que estas tres comunidades presentan de base un sentimiento de identidad y alegría de pertenecer a sus territorios, a pesar de la estigmatización y exclusión social.

\subsection{Sostenibilidad}

El criterio de sostenibilidad se comprende desde el proceso autosostenible por parte de la comunidad y desde la continuidad de procesos por parte de las Facultades y la comunidad académica. Se evidenció:

- Una presencia de corto plazo por parte de los estudiantes y docentes pertenecientes a las diferentes facultades en las comunidades, lo cual no permite una permanencia de la acción con mejores resultados.

- Se debe afianzar una articulación y alianza de los diferentes sectores solidario, privado y público, para que se logre la sostenibilidad de los proyectos.

- Falta asignar mayores recursos económicos para el desarrollo de los proyectos.

- Se deben afianzar procesos de visibilización y socialización del proyecto de intervención en su aspecto psicosocial como un modelo en diferentes ámbitos de asentamientos de población.

La USTA tiene en los Centros de Proyección Social una experiencia acumulada valiosa y un enorme potencial para hacer transcender la relación "Producción de Conocimiento - Investigación - Proyección Social, desde lo micro a lo macro, a través de sinergias que contribuyan a transformaciones sociales de mayor impacto en la ciudad. El ejercicio de la planeación, desde la perspectiva de la Unidad de Proyección Social, debe ser consistente con los ejercicios de planeación de las Facultades y con la naturaleza de las realidades de los entornos inmediatos y mediatos de los CPS. No es un ejercicio fácil, pero las Facultades y la Unidad de Proyección Social, bajo la 
orientación de la Vice-Rectoría Académica, deberán crear las condiciones apropiadas para dar coherencia lógica a las intervenciones en los territorios.

\section{Pautas para la construcción de un modelo de actuación de la Proyección Social en la USTA}

- La USTA debe promover espacios de reflexión sobre las funciones sustantivas de Producción de Conocimiento, Investigación y Proyección Social, de manera que directivos, docentes y estudiantes comuniquen conceptos consensuados y expresen en un mismo lenguaje las orientaciones normativas e institucionales y las acciones prácticas de la proyección social desde la naturaleza de cada programa académico. Sobre esta iniciativa, Fr. Adalmiro Arias O.P. ha comenzado a institucionalizar un grupo de personas de diversas Facultades que pueden contribuir a este propósito, bajo la orientación y dirección de la Vice-Rectoría Académica y en coordinación con la Unidad de Proyección Social.

- Un ejercicio de planeación de la investigación-proyección social se hace necesaria en cada Facultad, con prontitud. La USTA deberá elaborar el nuevo Plan de Desarrollo. Es el momento apropiado para que el ejercicio de la planeación en las Facultades se articule al ejercicio de formulación del Plan de Desarrollo de la Universidad para el próximo cuatrienio. También lo es para que, desde la Vice-Rectoría Académica y la Unidad de Proyección Social, se articulen los distintos planes de las Facultades, se garantice la interdisciplinariedad y se pueda tener una visión global, plausible, de la evolución de la proyección social en la USTA, durante los próximos años.

- Seleccionar un conjunto de indicadores que permitan una visión gerencial de la proyección social (Figura 7. En la Tabla 3 se sugieren algunos indicadores). Es necesario que a la luz de esos indicadores, la USTA pueda tener elementos de evaluación de impacto de la proyección social en el medio externo y pueda compararse a sí misma, en términos ínter-temporales, sobre las transformaciones que busca en las relaciones Producción de Conocimiento - Investigación, Producción de Conocimiento - Proyección Social e Investigación - Proyección Social.

- Buscar que los planes de investigación-proyección social establezcan escenarios de actuación que transcienda la visión micro (atención a personas). Los impactos en las dimensiones macro, meso o meta posicionarán mejor a la USTA, conforme a los alcances establecidos en sus objetivos misionales y en la visión de largo plazo. 
Figura 7

Ámbito de Relaciones e Indicadores

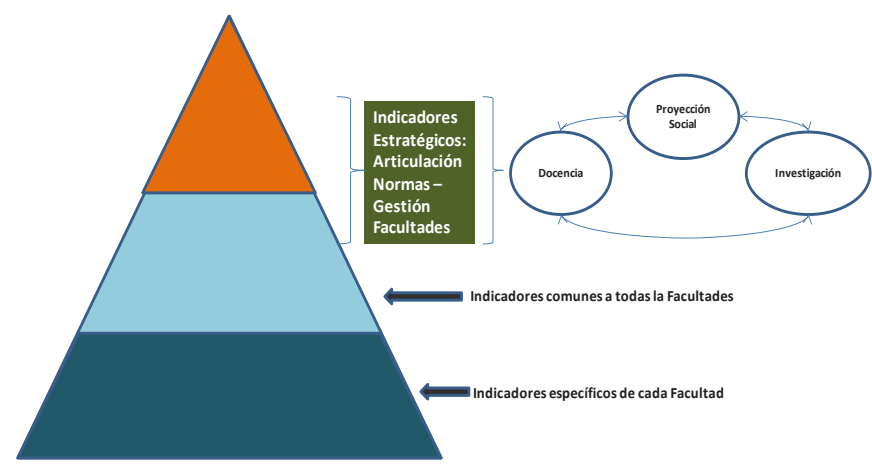

Fuente: Elaboración propia

Tabla 3. Indicadores para la evaluación de la proyección social-extensión

\begin{tabular}{|c|c|c|}
\hline ÁREA & DIMENSIÓN & INDICADOR \\
\hline \multirow{10}{*}{$\begin{array}{c}\text { Transferencia de } \\
\text { Conocimiento }\end{array}$} & \multirow{8}{*}{$\begin{array}{c}\text { Derivada de la acumulación } \\
\text { de saberes en docencia e } \\
\text { investigación }\end{array}$} & Cantidad de estudiantes en práctica/ año \\
\hline & & Existencia de convenios de práctica \\
\hline & & Existencia de tesis y otros estudios derivados de la academia sobre el entorno, \\
\hline & & Existencia de consultorios en los que participan estudiantes (empresariales, psicológicos, juridicos, etc.) \\
\hline & & Cantidad de proyectos de asesoría y consultoría contratados / año \\
\hline & & Cantidad de proyectos gestionados / año \\
\hline & & Cantidad de proyectos de investigación gestionados / año \\
\hline & & Cantidad de programas y proyectos promovidos o en los que participa la Universidad laño \\
\hline & \multirow{2}{*}{$\begin{array}{c}\text { Comunicación y } \\
\text { transferencia de cultura y } \\
\text { valores }\end{array}$} & Cantidad de programas radiales, de tv, revistas, periódicos externos \\
\hline & & Apariciones periódicas en medios \\
\hline \multirow{6}{*}{$\begin{array}{l}\text { Impacto y } \\
\text { reconocimiento en el } \\
\text { entorno }\end{array}$} & \multirow{6}{*}{$\begin{array}{c}\text { Contribución a la solución } \\
\text { de problemas especificos de } \\
\text { la sociedad }\end{array}$} & Cantidad de proyectos locales, regionales, nacionales de desarrollo en los que participa la institución/ año \\
\hline & & Población beneficiada con los proyectos de desarrollo de la institución/año \\
\hline & & Población beneficiada con los proyectos de desarrollo de la institución/población del área de influencia \\
\hline & & Cantidad de proyectos con efectos positivos / año \\
\hline & & Cantidad de proyectos interdisciplinarios de investigación orientados a la solución de problemas del desarrollo \\
\hline & & Registro de transformaciones que hacen los egresados en el entorno/año \\
\hline \multirow{13}{*}{ Gestión } & \multirow{2}{*}{ Politica } & Existencia de un marco conceptual para la función \\
\hline & & Existencia de un marco normativo para la función \\
\hline & \multirow{11}{*}{ Modelo } & Existencia de políticas que regulen intereacción con el entorno \\
\hline & & Existencia de un plan de proyección social \\
\hline & & Existencia de reglas de participación de la comunidad en los planes de proyección social \\
\hline & & Existencia de un área o dependencia responsables de la coordinación de los programas y proyectos de interacción con el entorno \\
\hline & & Destinación de recursos para la proyección social / año \\
\hline & & Existencia y aplicación en la institución de un modelo para la gestión del conocimiento y la reflexión epistemológica \\
\hline & & Existencia y aplicación en la institución de un modelo de responsabilidad social universitaria \\
\hline & & Existencia y divulgación de un balance social// año \\
\hline & & Existencia de un sistema de información \\
\hline & & Existencia de instrumentos de evaluación \\
\hline & & Existencia de informes periodicos \\
\hline \multirow{5}{*}{$\begin{array}{l}\text { Apropiación del } \\
\text { conocimiento }\end{array}$} & \multirow{5}{*}{$\begin{array}{c}\text { Comprensión y apropiación } \\
\text { de los saberes sociales y de } \\
\text { la realidad }\end{array}$} & Existencia de ajustes en el curriculo derivados del análisis del entorno \\
\hline & & Cantidad de estudiantes y profesores que participan en programas de proyección social /año \\
\hline & & Cantidad de investigadores externos vinculados a proyectos institucionales de investigación /año \\
\hline & & Cantidad de observatorios existentes \\
\hline & & Existencia de diagnósticos sobre la realidad del entorno \\
\hline \multirow{5}{*}{$\begin{array}{l}\text { Conceptualización y } \\
\text { Política Institucional }\end{array}$} & \multirow{2}{*}{ Marco Teorico Conceptual } & Declaración en el PEI sobre la identidad, principios, funciones, aspiraciones de esta función \\
\hline & & Existencia de un documento que contenga los lineamientos teóricos, conceptuales y metodológicos para esta función \\
\hline & \multirow{3}{*}{ Modelo de Excelencia } & Existencia de un modelo de esta función. \\
\hline & & Existencia de mecanismos para el mejoramiento continuo de esta función: planeación, gestión, monitoreo, control y evaluación \\
\hline & & Existencia de mecanismos para la articulación de la investigación, docencia y proyección social \\
\hline
\end{tabular}




\begin{tabular}{|c|c|c|}
\hline ÁREA & DIMENSIÓN & INDICADOR \\
\hline \multirow{4}{*}{$\begin{array}{l}\text { Articulación de } \\
\text { Funciones }\end{array}$} & \multirow{4}{*}{$\begin{array}{l}\text { Visibilidad de la docencia y } \\
\text { la invetigación articuladas }\end{array}$} & Aportes al mejoramiento de las organizaciones derivadas de productos investigativos contratados. \\
\hline & & Aportes al mejoramiento de las organizaciones derivadas de la participación de sus empleados en los cursos de formación \\
\hline & & Transformaciones en las organizaciones derivadas de las prácticas. \\
\hline & & Porcentaje de acciones de proyección social derivadas de la articulación con la investigación y la docencia \\
\hline \multirow{16}{*}{$\begin{array}{c}\text { Gestión de la } \\
\text { Proyección Social }\end{array}$} & \multirow{6}{*}{$\begin{array}{c}\text { Planeación, financiación y } \\
\text { evaluación }\end{array}$} & Recursos externos generados por los grupos y proyectos de investigación. \\
\hline & & Aportes de la proyección social al presupuesto de ingresos de la institución. \\
\hline & & Grado de conocimiento de la comunidad académica sobre las políticas y logros de esta función. \\
\hline & & Estudios sobre el entorno. \\
\hline & & Evaluaciones sobre los impactos de la función. \\
\hline & & Grado de autostenibilidad de las acciones de esta función \\
\hline & \multirow{8}{*}{ Impacto en la institución } & Competencias desarrolladas en los estudiantes como resultado de su participación en las prácticas. \\
\hline & & Competencias desarrolladas en los profesores como resultado de su participación en acciones de proyección social. \\
\hline & & Transformaciones curriculares en los programas académicos debido a la evaluación de las prácticas. \\
\hline & & Transformaciones curriculares en programas académicos por proyectos de investigación - docencia aplicados al entorno. \\
\hline & & Transformaciones de saberes disciplinares debido a las acciones de proyección social. \\
\hline & & \begin{tabular}{|l} 
Espacios para análisis del entorno, iiniciativas sociales en el curriculo, presencia en el plan de estudios de problemas del entorno. \\
.
\end{tabular} \\
\hline & & Transformaciones en gestión de proyección social derivadas de la evaluación de la pertinencia y responsabilidad de ella. \\
\hline & & Alianzas internas para la realización de la función. \\
\hline & \multirow{2}{*}{ Impacto en el entorno } & Aportes de la institución a políticas, proyectos, iniciativas de la educación superior. \\
\hline & & $\%$ de satisfacción de los beneficiarios de esta función. \\
\hline
\end{tabular}

Fuente: Universidad Santo Tomás, con base en APONTE, C. - ASCUN (2007)

\section{Conclusiones y Recomendaciones}

\subsection{Conclusiones}

Sobre información, planeación, seguimiento y evaluación

- La información sobre proyección social es uno de los temas que la USTA deberá comenzar a resolver. La cantidad y la calidad de la información es escasa, dispersa, incompleta y no responde a patrones de organización y sistematización. Una buena proporción de la información recolectada para la investigación corresponde a informes incidentales de gestión.

- Las Facultades no han adelantado de manera convencional procesos de planeación sobre la proyección social. Sin evidencias de procesos de planeación y con información insuficiente y no organizada, se dificultó la construcción de una línea de base con indicadores para la evaluación y, por tanto, la evaluación de impacto.

- Las Facultades y los Centros de Proyección Social, realizan un conjunto de actividades valiosas que se no se registran en ningún medio y, por lo tanto, no se hacen visibles. Las Facultades realizan acciones de proyección social que se pueden categorizar como desarrollo comunitario, no necesariamente en el ámbito de los CPS. Estas acciones evidencian un relación más fuerte entre investigación-proyección social.

- Se observa la ausencia de mecanismos que permitan la verificación y la evaluación permanente de las interrelaciones de la proyección social y la extensión con las funciones sustantivas de investigación y docencia. 
Sobre la proyección social en el ámbito del Programa Desarrollo Comunitario

- Se constata una diversidad de imaginarios sobre la proyección social, extensión e interacción con el medio.

- Existe un desencuentro relativo entre los lineamientos normativos e institucionales de la USTA y la actuación de las Facultades en proyección social.

- Las Facultades y la Unidad de Proyección Social, expresan un activismo voluntarioso de proyección social, sin referentes precisos acerca de las problemáticas sensibles del país, desde la perspectiva de cada disciplina. Esta situación es producto de la falta de planeación en este tema y de un análisis previo acerca de los problemas del país sobre los cuales centrar las acciones de investigación-docencia-proyección social.

- Las acciones de la proyección social a través del programa Desarrollo Comunitario, se han caracterizado por un énfasis de lo micro (personas) -se destaca más la interfaz con el beneficiario que con la corresponsabilidad interinstitucional y sectorial-. Es probable que esta situación sea la que suscita la asociación de la proyección social al asistencialismo social.

- La relación entre proyección social e investigación es baja: los trabajos de grado y de investigación corresponden al $11.2 \%$ de los proyectos analizados para el periodo 2000-2010. El peso de las actividades investigación, informes (...) recae en los estudiantes, casi en su totalidad.

- Se percibe la proyección social como acción puesta en práctica, como el desarrollo de estamentos que permiten que los estudiantes conozcan realidades concretas que los lleven a una visión disciplinar, crítica y social, desde la orientación de un docente.

- La mayoría de proyectos se encuentran en la línea estratégica de Educación.

- La ausencia de trabajos de investigación por parte de los docentes en las actividades que se desarrollan a través de los centros de proyección social, pareciera indicar que los docentes asumen un rol de orientadores de las actividades de los alumnos.

\subsection{Recomendaciones}

- Fr. Adalmiro Arias O.P., ha estructurado el Documento Maestro de la Proyección Social de la USTA. En torno a esa iniciativa, el Padre hizo una primera convocatoria a un grupo de docentes y de personas vinculadas al área administrativa de la universidad, con el fin de crear un espacio de reflexión y construcción de un proceso que permita ubicar la Proyección Social en 
el mismo nivel de importancia que actualmente tienen la Producción de Conocimiento y la Investigación. Se recomienda a la Vice-Rectoría Académica dar status institucional a la iniciativa de Fr. Adalmiro Arias O.P., y al grupo conformado, del que debe hacer parte la Unidad de Proyección Social, para orientar un proceso ordenado que incluya la planeación, la coordinación y la articulación sobre el tema entre Facultades y entre éstas con la Unidad de Proyección Social.

- Desde el punto de vista organizacional, las facultades deberían crear el Comité de Proyección Social-Extensión ${ }^{45}$. Sería de interés y beneficio para la orientación de las acciones de proyección social-extensión, que se vinculara ad hoc, a cada Comité, algunas representaciones de organizaciones externas, en concordancia con cada disciplina:

- Un representante del sector empresarial

- Un representante del sector gobierno (Nacional o local)

La institucionalización de los Comités, establecerá una nueva modalidad de relación entre las Facultades y la Unidad de Proyección Social. Es necesario que las Facultades asuman y ejerzan el liderazgo de la proyección social - extensión.

- Realizar/promover desde la Vice-Rectoría Académica, durante el 2011, en cada Facultad:

- Una dinámica que contribuya a esclarecer y ampliar la comprensión acerca de las nociones de proyección social-extensión en la comunidad académica de la USTA.

- Un proceso de planeación que articule la proyección social con la investigación y la docencia. La articulación entre proyección social investigación debe ser explícita, medible y evaluable; es una condición necesaria y suficiente. Desde ella podrá impactarse el currículo y la docencia. En la planeación, cada Facultad podrá hacer visible y verificable la articulación y tendrá un nuevo escenario que las lleve a superar el discurso o el activismo sin norte.

- Articular el proceso de planeación de la proyección social, al Plan de Desarrollo de la USTA del próximo cuatrienio (2011-2015).

- El ejercicio de la planeación implica, para cada Facultad, análisis y priorización de los problemas del país -y de Bogotá, como entorno próximo-. El análisis les permitirá establecer un horizonte de actuación en investigación y proyección social.

45 Algunas Facultades lo tienen, caso Contaduría que lo creó en junio de 2009. 
- Promover alcances macro, meta y meso de la proyección social, desde cada Facultad.

- Acoger una base mínima de indicadores, con base en el conjunto de indicadores propuestos en la Tabla 3, para el seguimiento periódico de la proyección social y la evaluación de impacto.

- Promover en la Facultades una participación más activa de los docentes para articular proyección social con investigación. Una categoría de docentesinvestigadores en proyección social se hace necesaria.

\section{REFERENCIAS BIBLIOGRÁFICAS}

Aponte, C. (2007) Propuesta de indicadores de evaluación de la función de proyección social/ extensión universitaria/ interacción en la educación superior. ASCUN. Bogotá, Colombia.

Arias Adalmiro, (2010). Hacia la Nueva Imagen de la Proyección Social de la USTA. Documento Maestro de la Proyección Social, Bogotá. Mimeo.

Martínez, M. E. (2007). Marco conceptual y taxonomía de la proyección social en la Universidad de la Sabana. Chía, Cundinamarca, Colombia.

Murcia Yury y Torres Yury (2009). Sentido y Experiencia de la Proyección Social. Altos de Cazucá, Comuna IV. Universidad Santo Tomás, Facultad de Filosofía y Letras. Mimeo.

Pontificia Universidad Javeriana - Vicerectoría Académica (2002). Prácticas Sociales Universitarias: Una estrategia para la proyección social en la formación de los estudiantes de pregrado. Bogotá, Colombia.

Ramírez, A. M. (2004). Proyección Social Universidad de la Sabana. Chía, Cundinamarca, Colombia.

Universidad del Rosario (2010). De la extensión a la responsabilidad social universitaria: competitividad con cohesión social. Bogotá.

Universidad Santo Tomás (2005). Proyecto Educativo Institucional -PEI-. http:// www. usta.edu.co/documents/generales/PEI.pdf

Universidad Santo Tomás (2004). Política Curricular.

Universidad Santo Tomás - Vicerectoría Académica - Unidad de Proyección Social y Extensión Universitaria (2005). Contexto, Fundamento y Frentes de Trabajo de la Proyección Social en la USTA. Bogotá. Mimeo. 
Universidad Santo Tomás - Facultad de Economía (2006). Lineamientos y Características Generales de la Proyección Social. Bogotá. Mimeo.

Universidad Santo Tomás - Unidad de Proyección Social (2007). Fundamentos, Políticas, Instrumentos y Desarrollo de la Proyección Social y Extensión Universitaria en la USTA. Bogotá. Mimeo.

Universidad Santo Tomás - Facultad de Contaduría Pública (2009). Informe de Gestión 2008-2009. Extensión y Proyección Social. Bogotá. Mimeo.

Universidad Santo Tomás - Facultad de Ingeniería Mecánica (2009). Proyección Social. Bogotá. Mimeo.

Universidad Santo Tomás - Facultad de Economía (2010). Lineamientos y Características Generales de la Proyección Social. Bogotá. Mimeo.

Universidad Santo Tomás - Facultad de Ingeniería Electrónica (). 
Anexo. Esquema de Evaluación - MML

\begin{tabular}{|c|c|c|}
\hline \multicolumn{3}{|c|}{$\begin{array}{l}\text { Esquema de Evaluación } \\
\text { Adecuación de las etapas de formulación, ejecución y resultados }\end{array}$} \\
\hline Formulación & Ejecución & Resultados \\
\hline Antecedentes y contexto & \multirow[b]{3}{*}{$\begin{array}{l}\text { Programas, proyectos y } \\
\text { actividades por Facultad }\end{array}$} & \multirow[t]{2}{*}{$\begin{array}{l}\text { Objetivos misionales de la } \\
\text { Proyección Social por Facultad }\end{array}$} \\
\hline Participación de actores & & \\
\hline $\begin{array}{l}\text { Coherencia de las prácticas } \\
\text { de proyección social con los } \\
\text { objetivos misionales de la } \\
\text { USTA (EO y PEI) }\end{array}$ & & Resultados \\
\hline
\end{tabular}

\section{Diseño del marco lógico}

\begin{tabular}{|l|c|}
\hline 1. Análisis de involucrados & \multirow{2}{*}{ Diagnóstico } \\
\cline { 1 - 1 } 2. Análisis de Problemas & \\
\cline { 1 - 1 } 3. Análisis de Objetivos & \multirow{2}{*}{ Situación futura } \\
\hline 4. Análisis de Alternativas & \\
\hline 5. Matrices & \\
\hline
\end{tabular}

\section{Eslabonamientos}

\begin{tabular}{|c|c|c|c|}
\hline Actividades & Componentes & Propósito & Fin \\
\hline \multirow[b]{2}{*}{ Insumos } & Resultados (metas) & \multirow{2}{*}{$\begin{array}{l}\text { Lo que cada división esperaba } \\
\text { que permaneciera en el proyecto } \\
\text { (Objetivos específicos por } \\
\text { Facultad): EFECTOS DIRECTOS }\end{array}$} & \multirow[b]{2}{*}{$\begin{array}{l}\text { Objetivos Misionales } \\
\text { Globales (¿IMPACTOS?) }\end{array}$} \\
\hline & Productos & & \\
\hline
\end{tabular}

\begin{tabular}{|l|l|l|l|l|l|l|l|}
\hline \multicolumn{7}{c|}{ Modelo Matriz del Marco Lógico } \\
\multicolumn{1}{c|}{ Título Objetivos $\begin{array}{c}\text { Nombre del } \\
\text { Indicador }\end{array}$} \\
\hline
\end{tabular}

\begin{tabular}{|c|c|c|c|c|c|c|c|}
\hline \multirow[b]{2}{*}{ Producto } & \multicolumn{6}{|c|}{ Modelo Matriz del Actividades y Recursos por Resultados / Productos } & \multirow[b]{2}{*}{ Recursos } \\
\hline & Objetivo & Actividades & Inicio & Finalización & Inicio & Finalización & \\
\hline $\begin{array}{l}\text { Objetivos } \\
\text { específicos p } \\
\text { Facultad }\end{array}$ & & & & & & & \\
\hline $\begin{array}{l}\text { Resultado o } \\
\text { producto } 1\end{array}$ & & & & & & & \\
\hline $\begin{array}{l}\text { Resultado o } \\
\text { producto } 2\end{array}$ & & & & & & & \\
\hline $\begin{array}{l}\text { Resultado o } \\
\text { producto } \mathrm{n}\end{array}$ & & & & & & & \\
\hline
\end{tabular}

